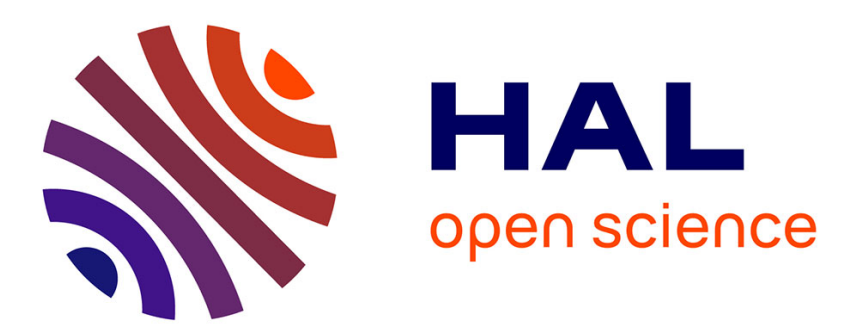

\title{
Overpressure development in sedimentary basins induced by chemo-mechanical compaction of sandstones
}

A. Brüch, N. Guy, S. Maghous

\section{To cite this version:}

A. Brüch, N. Guy, S. Maghous. Overpressure development in sedimentary basins induced by chemo-mechanical compaction of sandstones. Marine and Petroleum Geology, 2019, 104, pp.217-230. 10.1016/j.marpetgeo.2019.03.025 . hal-02122951

\section{HAL Id: hal-02122951 \\ https://hal-ifp.archives-ouvertes.fr/hal-02122951}

Submitted on 7 May 2019

HAL is a multi-disciplinary open access archive for the deposit and dissemination of scientific research documents, whether they are published or not. The documents may come from teaching and research institutions in France or abroad, or from public or private research centers.
L'archive ouverte pluridisciplinaire HAL, est destinée au dépôt et à la diffusion de documents scientifiques de niveau recherche, publiés ou non, émanant des établissements d'enseignement et de recherche français ou étrangers, des laboratoires publics ou privés. 


\title{
OVERPRESSURE DEVELOPMENT IN SEDIMENTARY BASINS INDUCED BY CHEMO-MECHANICAL COMPACTION OF SANDSTONES
}

\author{
A. Brüch ${ }^{1 *}$, N. Guy 1 , S. Maghous ${ }^{2}$ \\ ${ }^{1}$ IFP Energies nouvelles, 1 et 4 avenue de Bois-Préau, 92852 Rueil-Malmaison, France \\ ${ }^{2}$ Department of Civil Engineering, Federal University of Rio Grande do Sul, Porto Alegre, Brazil \\ * Corresponding author. \\ E-mail address: andre.reinert-bruch @ifpen.fr
}

\begin{abstract}
Mechanisms of overpressure build-up resulting from chemically-induced compaction are investigated by considering that intergranular pressure-solution, controlled by temperature and effective stresses, is the dominant process of chemical deformation in sandstones. The numerical simulations are performed using a thermo-poro-mechanical tool based on the finite element method specifically devised to deal with sedimentary basin modeling. At the material level, purely mechanical and chemo-mechanical deformations are respectively addressed by means of plastic and viscoplastic constitutive components. Porosity data of the Middle Jurassic Garn Formation from the Haltenbanken area of the MidNorwegian Continental Shelf are taken as reference for calibration of the sandstone model to be used on synthetic cases of a siliciclastic basin in oedometric conditions. Two situations are proposed involving different depositional sequences of sandy and shaly sediments with the aim to assess the permeability effect in the numerical model. The results have shown that early overpressure development in low permeability formations preserves sandstone porosities by reducing effective stresses and thus retarding pressure-solution compaction, whereas higher effective stresses associated with permeable depositional environments may lead to important chemo-mechanical deformation, resulting in low porosity sandstones and significant overpressure generation at later stages of basin history. An additional case is finally analyzed to investigate the consequences of pressure-solution inhibition due to diagenetic grain coating in a sandstone reservoir. The simulation resulted in porosity preservation and lower overpressure values, showing that a sedimentary basin submitted to an important level of chemo-mechanical compaction can present substantially higher overpressure distribution than basins where this phenomenon did not take place. The paper highlights the importance of integrating stresses, fluid pressure and temperature to represent the porous material evolution in order to describe the geological state of sedimentary basins.
\end{abstract}

Keywords: sedimentary basin, intergranular pressure-solution, overpressure, chemomechanical compaction, coupled geomechanics, finite element method. 


\section{INTRODUCTION}

It is well known that dissolution and precipitation of minerals may play an important role in the porosity reduction of siliciclastic and carbonate rocks. Several works have been published on this topic in the last decades, including microscopic models, laboratory tests and field data in an attempt to describe the complex aspects of these phenomena (Dewers and Hajash, 1995; Dove, 1999; Gratier and Irigm, 1986; Gundersen et al., 2002; Lehner, 1995; Meng et al., 2003; Neveux et al., 2014; Raj, 1982; Rutter, 1976; Schutjens and Spiers, 1999; Shimizu, 1995; Weyl, 1959; Zhang and Spiers, 2005). However, it is still a difficult task to formulate a macroscopic material model to include chemical compaction in sedimentary basin simulators and predict the impact of these diagenetic processes through geological time on the evolution of hydrocarbon systems. As a consequence, reconstruction of the porosity history is commonly performed in basin modeling by considering only mechanical compaction together with simplified constitutive models that are calibrated to fit available data without distinguishing the different factors involved in porosity change. In many cases these models can provide good accuracy for porosity distribution and overall basin deformation down to a certain depth but cannot predict overpressure build-up associated with chemical compaction which may strongly affect fluid migration and accumulation, impacting on reserve assessment and risk evaluation (Crook et al., 2018; Gavrilenko and Gueguen, 1993; Obradors-Prats et al., 2017). Despite the difficulties in developing comprehensive constitutive models for the sediment material, integration of both mechanical and chemical compaction in numerical tools is essential to better describe the geological state of sedimentary basins and further progress must be achieved in that direction.

In this context, many efforts have been done to understand the different deformation mechanisms of sandstones since most of the hydrocarbon reservoirs can be found in this type of sedimentary rock. However, some divergences persist in literature concerning the nature of the chemically-induced compaction leading to important porosity reduction of quartzose rocks in deeper layers of sedimentary basins. The two predominant theories agree that temperature plays a key role on the whole process by affecting minerals kinetics, the main difference lies in the fact that some authors consider that the dominant mechanism is a stress independent phenomenon known as illite-mica induced dissolution (IMID) (Bjorkum, 1996; Bjorkum and Nadeau, 1998; Maast, 2017), while others state that several evidences indicate that the process is in fact a stress induced compaction, which is referred to as intergranular pressure-solution (IPS) (Osborne and Swarbrick, 1999; Sheldon et al., 2003; Stricker et al., 2016; Stricker et al., 2017).

This work considers that IPS is the dominant mechanism of chemical compaction and divides the deformation processes of sandstones in two types. The first is purely mechanical compaction through pore fluid expulsion and grain rearrangement associated to overburden increase. The second is chemo-mechanical porosity reduction resulting from three sequential steps, the slowest of them controlling the overall process: mineral dissolution at grain contact, material transport through diffusion and precipitation on the free walls of near grains. Purely mechanical deformation prevails in the early stages of a newly deposited layer whilst chemomechanical compaction takes place as progressive burial increases sediments temperature and effective stresses (Schmidt and McDonald, 1979; Tada and Siever, 1989).

Most investigations on pressure-solution in sandstones refer to cases located in the North Sea (Ramm, 1992; Ramm and Bjorlykke, 1994; Walderhaug et al., 2000). The process occurs through dissolution and precipitation of quartz which starts at depths beyond 1.5 to $2 \mathrm{~km}$ at temperatures around $60^{\circ} \mathrm{C}$ and can become the dominant deformation mechanism below 2 to $3 \mathrm{~km}$ burial depth where temperatures exceed $80^{\circ} \mathrm{C}$, possibly preventing further mechanical 
compaction due to the amount of grain cementation as the reaction rates increase with increasing temperature (Bjorlykke, 2014; Niemeijer et al., 2002; Renard et al., 1997; Schneider et al., 1996). Nevertheless, it seems that some factors, as the presence of hydrocarbons or grain coating, may retard or totally inhibit pressure-solution even at great depths (de Boer et al., 1977; Ehrenberg, 1993; Mullis, 1993; Worden and Morad, 2000). In general it is acceptable to consider that an initial porosity of $40-45 \%$ for sands decreases by means of mechanical compaction alone down to $24-34 \%$ and that further reduction is only possible through mineral dissolution which can lead to porosity levels of $4-10 \%$ at depths below 4 km (Lander and Walderhaug, 1999; Ramm, 1992; Renard et al., 1999; Schneider and Hay, 2001; Walderhaug et al., 2000; Yang, 2000).

A proper modeling of mechanical and chemo-mechanical deformation in the macroscopic scale requires understanding their relation with effective stresses and pore fluid pressure. In the mechanical compaction sequence it is the overpressure dissipation through fluid expulsion that leads to higher effective stresses on the mineral structure reducing porosity through grain reorientation, sliding, deformation and breakage. In the chemo-mechanical sequence the current effective stresses promote the dissolution of minerals which will be transported and precipitated in regions of lower concentration, reducing the pore spaces and increasing fluid pressure. The first deformation mechanism is related to overpressure dissipation and the latter to overpressure build-up. As a consequence, the resulting overpressure will increase fluid flow rates in a permeable zone but will not be easily dissipated in a low permeability environment. Eventually, it may decrease the effective stress state to a certain level that will stop the compaction process (Angevine and Turcotte, 1983; Anzalone et al., 2006; Stricker et al., 2016), but some authors report that the resulting fluid pressure may even induce fracturing of top seal rocks (Bjorkum and Nadeau, 1998; Schneider and Hay, 2001; Wangen, 2000). The reproduction of these geological scenarios is only possible if both phenomena are accordingly taken into account in the numerical basin simulator.

Based on previous concepts presented in Maghous et al. (2014) for mechanical compaction, a macroscopic isothermal poromechanical constitutive model and a three-dimensional finite element algorithm have been developed in Brüch et al. (2016) to deal with mechanical and chemo-mechanical deformations and later extended in Brüch et al. (2018) to take temperature effects into account. Purely mechanical and chemo-mechanical deformations are respectively addressed by means of plastic and viscoplastic components in the macroscopic state equations of the sediment material. The proposed model for IPS compaction assumes solid volume conservation by considering that the dissolved minerals precipitate at short distances compared to basin scale.

A synthetic case of a siliciclastic sedimentary basin in oedometric conditions is used to illustrate the constitutive model behavior. First, sandstone and shale models are respectively characterized through a single material basin in sections 3.1 and 3.2: the sandstone is considered to compact through both mechanical and chemo-mechanical processes whilst the shale model undergoes only mechanical deformation. Then, two cases are presented in section 3.3 with different sandstone and shale stratigraphic sequences with the aim to change the permeability of the system. The results are analyzed focusing on the connection between effective stresses, temperature, pore fluid pressure and porosity change induced by intergranular pressure-solution. For last, an additional simulation is proposed in section 3.4 to investigate the limit situation in which IPS phenomenon is totally inhibited by grain coating. The contribution of chemo-mechanical compaction to porosity reduction and associated overpressure generation within sedimentary basins is specifically assessed by comparison of the results obtained from the numerical simulations carried out in sections 3.3 and 3.4. 


\section{THEORETICAL ASPECTS}

The thermo-poro-mechanical basin simulator and associated theoretical framework presented in Brüch et al. (2018) will be used in the subsequent analysis. The main difference with respect to basin simulators that use classical compaction models based on phenomenological relationships relating porosity to effective vertical stress is that the present relies on a tensorial formalism of the constitutive model. This is necessary to model complex geological configurations, including lateral deformations induced by tectonics which may lead to important overpressure build-up, seal rock fracturing and fault reactivation, which in turn would directly affect the migration flow path (Crook et al., 2018; Maghous et al., 2014; Obradors-Prats et al., 2017).

The finite element numerical tool uses twenty-node hexahedra elements for geometry discretization and unknown fields interpolation. Displacement fields are approximated through piecewise quadratic polynomial functions while piecewise linear polynomial functions are adopted for the interpolation of pore pressure and temperature fields (Zienkiewicz and Taylor, 2000). The formulation is based on the updated Lagrangian scheme (Bathe, 1996). The poromechanical problem is solved implicitly and then explicitly coupled with the thermal solution at the end of each time step (Felippa et al., 2001). An algorithm developed by Bernaud et al. (2006) is used to simulate sediments accretion periods by progressive activation of the gravity forces within a fictitious closed material system. The numerical procedure makes use of shared memory multiprocessing OpenMP interface for parallel computing (Chapman et al., 2008) with an automatic time-step algorithm that constantly updates the thermal and poromechanical time step lengths based on the evolution of the material properties and finite element mesh geometry to reduce computational costs.

The sediment material is considered as an isotropic fully saturated thermo-poro-elastoplasticviscoplastic medium undergoing large irreversible strains. The modeling is developed in the context of a single and incompressible saturating pore fluid. The reversible (elastic) strains and the reversible variations of porosity are assumed to remain infinitesimal. A key aspect of the model concerns the evolution of material constitutive and transport properties according to porosity and temperature changes by means of micromechanics reasoning and phenomenological laws. The model is briefly described in this section. Further information regarding the finite element algorithm and the porous material constitutive model can be found in Brüch et al. (2018).

\subsection{Field equations}

At the macroscopic scale a porous medium is viewed as the superposition of a solid continuum deformable skeleton and a fluid continuum occupying the porous space in constant thermal equilibrium (Coussy, 2004). Accordingly, the amount of fluid content in the current configuration is defined by the Eulerian porosity $\varphi$. Assuming a quasi-static evolution of the porous continuum, the equilibrium equation expresses:

$\operatorname{div} \underline{\underline{\sigma}}+\rho \underline{g}=0$

where $\underline{\underline{\sigma}}$ is the Cauchy total stress tensor, $\rho=(1-\varphi) \rho^{s}+\varphi \rho^{f}$ is the density of the porous material, with $\rho^{s}$ and $\rho^{f}$ respectively being the mass densities of the solid and fluid phases, and $\underline{g}$ is the acceleration of gravity.

The mass balance referring to the fluid flowing through the connected porous space reads: 


$$
\frac{d}{d t}\left(\rho^{f} \phi\right)+J \operatorname{div}\left(\rho^{f} \underline{q}^{f}\right)=0
$$

where $\phi$ is the Lagrangian porosity defined as the pore fluid fraction with respect to the initial configuration of the porous medium particle. It is related to the Eulerian porosity $\varphi$ through the Jacobian of the transformation $J, \phi=J \varphi$. Denoting by $\underline{\underline{K}}^{f}$ the permeability tensor of the porous medium, the filtration vector $\underline{q}^{f}$ is connected to the gradient of the pore fluid pressure $p$ following Darcy's law:

$\underline{q}^{f}=\underline{\underline{K}}^{f} \cdot\left(-\underline{\nabla} p+\rho^{f} \underline{g}\right)$

The temperature evolution is obtained disregarding the poromechanical contribution in the entropy balance of the porous material and by considering that conduction is the dominant heat transfer mode in the basin:

$\rho c \frac{d T}{d t}+\operatorname{div} \underline{q}^{t}=r^{t}$

where $c$ is the specific heat, $T$ is the temperature, $\underline{q}^{t}$ is the heat flow vector and $r^{t}$ is the heat generation per unit volume. The heat flow is defined by Fourier's law:

$\underline{q}^{t}=-\underline{\underline{K}}^{t} \cdot \underline{\nabla T}$

where $\underline{\underline{K}}^{t}$ is the thermal conductivity tensor of the porous medium.

\subsection{Constitutive equations}

Within the framework of large irreversible deformation and porosity variation the state equations of the porous material are defined in rate form taking into account the effects of microstructural changes on the evolution of the thermo-poroelastic properties (Bernaud et al., 2002; Dormieux and Maghous, 1999; Dormieux and Maghous, 2000). In the context of isotropy, the thermo-poromechanical state equations are formulated by considering the time derivative of the following relationships (Coussy, 2004):

$\Delta \underline{\underline{\sigma}}=\underset{\sim}{C}: \Delta \underline{\underline{\varepsilon}}^{e l}-b \Delta p \underline{\underline{1}}-3 K \alpha^{s} \Delta T \underline{\underline{1}}$

$\Delta \phi^{e l}=b \operatorname{tr} \Delta \underline{\underline{\varepsilon}}^{e l}+\frac{\Delta p}{M}-3 \alpha^{\phi} \Delta T$

where $\Delta \underline{\varepsilon}^{e l}$ and $\Delta \phi^{e l}$ refer respectively to the local infinitesimal elastic strain and porosity variation, computed with respect to the unstressed configuration of the porous medium

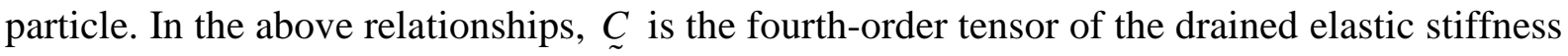
moduli, $K$ is the bulk modulus, $b$ and $M$ denote respectively the Biot coefficient and Biot modulus, $\alpha^{s}$ is the thermal dilation coefficient of the solid phase, $\alpha^{\phi}$ is the volumetric thermal dilation coefficient of the pores and $\underset{\underline{1}}{=}$ is the second-order identity tensor. 
Under the assumption of infinitesimal elastic strains, the Jacobian of the skeleton transformation defining the ratio between the porous element volume in its current and initial configurations can be approximated by the Jacobian of the irreversible transformation $J \approx J^{i r}$, which in turn can be split into its plastic and viscoplastic parts $J^{i r}=J^{p} J^{v p}$. In addition, the solid phase is assumed to be incompressible during the irreversible transformation, which means that any variation of the volume during plastic or viscoplastic deformations is only due to pore volume change. These considerations allow to compute the evolution of the Eulerian porosity as a function of $J^{\text {ir }}$ (Brüch et al., 2016):

$\varphi=1-\frac{1-\phi_{0}}{J^{i r}}$

\subsection{Plastic model}

An elastoplastic behavior is used to model purely mechanical compaction of the sediment material based on the Terzaghi effective stress $\underline{\underline{\sigma}}{ }^{\prime}=\underline{\underline{\sigma}}+p \underline{\underline{1}}$. The flow rule is associated and the plastic yield surface is taken from the modified Cam-Clay model, expressed as a function of the deviatoric stress tensor $\underline{\underline{s}}=\underline{\underline{\sigma}}-\operatorname{tr} \underline{\underline{\sigma}} / 3 \underline{\underline{1}}$ and the mean effective stress $p^{\prime}=\operatorname{tr} \underline{\underline{\sigma^{\prime}}} / 3$ (Wood, 1990):

$f^{p}\left(\underline{\underline{\sigma}}^{\prime}, p_{c}\right)=\frac{3}{2} \underline{\underline{s}}: \underline{\underline{s}}+M_{c s}^{2} p^{\prime}\left(p^{\prime}+p_{c}\right)$

where $M_{c s}$ is the slope of the critical state line and $p_{c}$ is the consolidation pressure controlling the size of the plastic yield surface.

The adopted plastic hardening law that describes the evolution of parameter $p_{c}$ with irreversible densification of the material can be viewed as an extension of the model originally proposed by Barthélémy et al. (2003) on the basis of micromechanical limit analysis reasoning. This micromechanics-based law has proved attractive in the context of sedimentary basin modeling since the consolidation pressure tends towards infinity when the pore space vanishes, thus preventing the development of negative porosities under high isotropic compression (Deudé et al., 2004). A first extension of the model has been proposed in Brüch et al. (2016) in order to take into account the effect of interdependent mechanical and chemo-mechanical deformation processes on the porosity reduction. However, the original hardening law developed in Barthélémy et al. (2003) as well as its extended version from Brüch et al. (2016) suffer mainly from the absence of calibration coefficients, and for this reason, they cannot represent accurately the specific behavior of different types of rocks. As reported in Brüch et al. (2018), this shortcoming leads to a non-realistic undeformed layer on the upper part of the basin, making it difficult to represent realistic porosity distribution such as those observed from sedimentary basins data. To circumvent the above difficulty and based on the same reasoning developed in Brüch et al. (2016), a new plastic hardening law involving an exponent parameter $m_{p}$ is proposed:

$$
p_{c}(\varphi)=p_{c 0}\left(\frac{\ln \varphi}{\ln \phi_{0}}\right)^{m_{p}}
$$




\subsection{Viscoplastic model}

Considering that the driving force for IPS compaction at the microscopic scale is the difference in effective stress between grain contacts and free pore walls, the chemomechanical time-dependent compaction is addressed at the macroscopic scale by means of a viscoplastic model based on the generalized Perzyna's overstress theory (Perzyna, 1966) with an associated flow rule (Brüch et al., 2016). The yield surface is taken from the Cam-Clay model with its size and the slope of the critical state line being respectively defined by $p_{v p}^{s}$ and $M_{v p}$. The viscoplastic strain rate $\underline{\underline{d}}^{v p}$ reads:

$\underline{\underline{d}}^{v p}=\frac{1}{\eta_{v p}}\langle\Phi(F)\rangle^{n_{p p}} \frac{\partial f_{d}^{v p}}{\partial \underline{\underline{\sigma}}^{\prime}}$

where $\langle\cdot\rangle$ is the Macaulay brackets, $\eta_{v p}$ is the viscosity coefficient, $n_{v p}$ is the viscosity exponent and $f_{d}^{v p}$ is a dynamic loading surface with the same shape as the yield surface but with its size controlled by a dynamic consolidation pressure $p_{v p}^{d}$ characterizing the magnitude of the current effective stress state of the porous material (Adachi and Oka, 1982; Yin and Hicher, 2008). A scaling function $\Phi(F)$ is used to verify if the material is undergoing viscoplastic deformation and to quantify the distance of its stress state with relation to the yield surface:

$\Phi(F)=F-1=\frac{p_{v p}^{d}}{p_{v p}^{s}}-1$

The static consolidation pressure $p_{v p}^{s}$ represents the hardening parameter of the viscoplastic model. It is considered that the rate of compaction decreases with increasing deformation as the contact surfaces between grains increase, thus reducing local grain-to-grain stresses that induce mineral dissolution (Dewers and Hajash, 1995; Renard et al., 1999). Relying upon a reasoning similar to that developed in plasticity, the following viscoplastic hardening law expressing a logarithmic dependence of $p_{v p}^{s}$ with respect to current porosity has been proposed in Brüch et al. (2016):

$p_{v p}^{s}(\varphi)=p_{v p 0}^{s}\left(\frac{\ln \varphi}{\ln \phi_{0}}\right)^{m_{v p}}$

where exponent $m_{v p}$ is a model parameter ranging between zero and $m_{p}$ that controls the relative magnitude of viscoplastic strains with respect to plastic strains in the constitutive model.

\subsection{Complementary laws}

In this work, the temperature effects on the evolution of the porous material properties will be restrained to the macroscopic viscoplastic viscosity coefficient that affects the chemomechanical strain rates and the pore fluid viscosity impacting fluid transport through the permeability law. The evolution of the viscoplastic viscosity coefficient $\eta_{v p}$ is given by an Arrhenius law (Rutter, 1983; Schneider et al., 1996): 
$\eta_{v p}(T)=\eta_{v p 0} \exp \left[\frac{E_{a}}{R}\left(\frac{1}{T_{K}}-\frac{1}{T_{K, 0}}\right)\right]$

where $T_{K}$ is the absolute temperature expressed in Kelvin, $\eta_{v p 0}$ is the viscosity coefficient at a reference temperature $T_{K, 0}(K), E_{a}$ is the activation energy and $R=8.31 \mathrm{~J} / \mathrm{K} \times \mathrm{mol}$ is the universal gas constant. Typical values found in the literature for the activation energy of pressure-solution in sandstones range from 15 to $30 \mathrm{~kJ} / \mathrm{mol}$ (Angevine and Turcotte, 1983; Bjorkum and Nadeau, 1998; Nakashima, 1995; Renard et al., 1997; Schneider and Hay, 2001; Shimizu, 1995).

Water is the only fluid saturating the pore space that will be considered in the subsequent analysis. Its viscosity coeficient $\eta^{f}$ is determined as follows, with $A=141.47 \mu \mathrm{Paxs}$, $B=226.8 \mathrm{~K}$ and $\alpha=-1.5914$ (Ulamec et al., 2007):

$\eta^{f}(T)=A\left(\frac{T_{K}}{B}-1\right)^{\alpha}$

The permeability coefficient $k^{f}$ of the porous medium is modeled through Kozeny-Carman formula (Coussy, 2004), where $k_{0}^{f}=k^{f}\left(\phi_{0}, T_{0}\right)$ and $\eta_{0}^{f}=\eta^{f}\left(T_{0}\right)$ are respectively the permeability coefficient and fluid viscosity at reference porosity $\phi_{0}$ and temperature $T_{0}$.

$k^{f}(\varphi, T)=k_{0}^{f} \frac{\varphi^{3}\left(1-\phi_{0}\right)^{2}}{\phi_{0}^{3}(1-\varphi)^{2}} \frac{\eta_{0}^{f}}{\eta^{f}(T)}$

The effect of microstructural changes on the poroelastic properties are quantified as a function of the porosity $\varphi$ according to the upper bounds of Hashin-Shtrikman for the bulk $K$ and shear $\mu$ drained moduli (Hashin, 1983), and by means of classical results of linear poroelasticity for the Biot coefficient $b$, Biot modulus $M$ and volumetric thermal dilation coefficient of the pores $\alpha^{\phi}$ (Coussy, 2004), where $k^{s}$ and $\mu^{s}$ are the bulk and shear moduli of the solid phase:

$$
\begin{aligned}
& K(\varphi)=\frac{4 k^{s} \mu^{s}(1-\varphi)}{3 k^{s} \varphi+4 \mu^{s}} \\
& \mu(\varphi)=\frac{\mu^{s}(1-\varphi)\left(9 k^{s}+8 \mu^{s}\right)}{k^{s}(9+6 \varphi)+\mu^{s}(8+12 \varphi)} \\
& b(\varphi)=1-\frac{K(\varphi)}{k^{s}} \\
& M(\varphi)=\frac{k^{s}}{b(\varphi)-\varphi}
\end{aligned}
$$




$$
\alpha^{\phi}(\varphi)=\alpha^{s}(b(\varphi)-\varphi)
$$

Regarding the thermal properties of the porous material, the specific heat $c$ is defined as the mass average of the specific heat of the solid $c^{s}$ and of the fluid $c^{f}$ (Somerton, 1992):

$$
c(\varphi)=\frac{\rho^{s}(1-\varphi) c^{s}+\rho^{f} \varphi c^{f}}{\rho}
$$

The thermal conductivity coefficient $k^{t}$ is determined adopting micromechanical estimates derived from Mori-Tanaka scheme, where $k^{t, s}$ and $k^{t, f}$ are the thermal conductivity coefficients of the solid and fluid phases, respectively (Stransky et al., 2011):

$$
k^{t}(\varphi)=k^{t, s} \frac{3 k^{t, f}+2(1-\varphi)\left(k^{t, s}-k^{t, f}\right)}{3 k^{t, s}+(1-\varphi)\left(k^{t, f}-k^{t, s}\right)}
$$

\section{FINITE ELEMENT SOLUTIONS}

Assessment of the geological history of the sedimentary basin requires the solution of the boundary value problems for large space domains and large time periods. The time evolution of the displacement, pore pressure and temperature fields are respectively obtained from the weak formulation of the equilibrium, mass and entropy balance equations together with the set of the constitutive equations, plastic and viscoplastic models, and complementary laws. The thermo-poro-mechanical models presented in this section are solved using the finite element basin simulator presented in Brüch et al. (2018).

The numerical simulations are restricted to the context of purely gravitational compaction within oedometric setting. No lateral deformation induced by tectonic sequences or thermal expansion are considered. All cases have the same boundary conditions, deposition rate and total thickness of supplied sediments. The difference between each case lies only on the stratigraphic distribution, which is achieved by varying the amount and type of the deposited materials.

The boundary conditions for the poromechanical and thermal problems are respectively shown in Fig. 1 and Fig. 2. The plane $z=0$ defines the basement rock assumed to be rigid and impermeable, with a constant upward heat flow $q^{t, d}=70 \mathrm{~mW} / \mathrm{m}^{2}$. The lateral surfaces have no lateral displacements, are impermeable and insulated. The sea level coincides with the top surface of the basin located at $z=H(t)$ which is kept at $T^{d}=10^{\circ} \mathrm{C}$ during all the simulation.

The studied cases correspond to a material system formed by the deposition of $8000 \mathrm{~m}$ of sediments with constant accumulation rate along $170 \mathrm{My}$, which results in approximately 47 $\mathrm{m}$ of deposited material per million years. The initial finite element mesh is a column $8000 \mathrm{~m}$ height regularly divided into 80 cubic hexahedra elements of side $L=100 \mathrm{~m}$ along the vertical direction. The total number of mesh nodes is equal to 968 , corresponding to 3552 total degrees of freedom: 2904 for displacement, 324 for pore fluid pressure and 324 for temperature. 


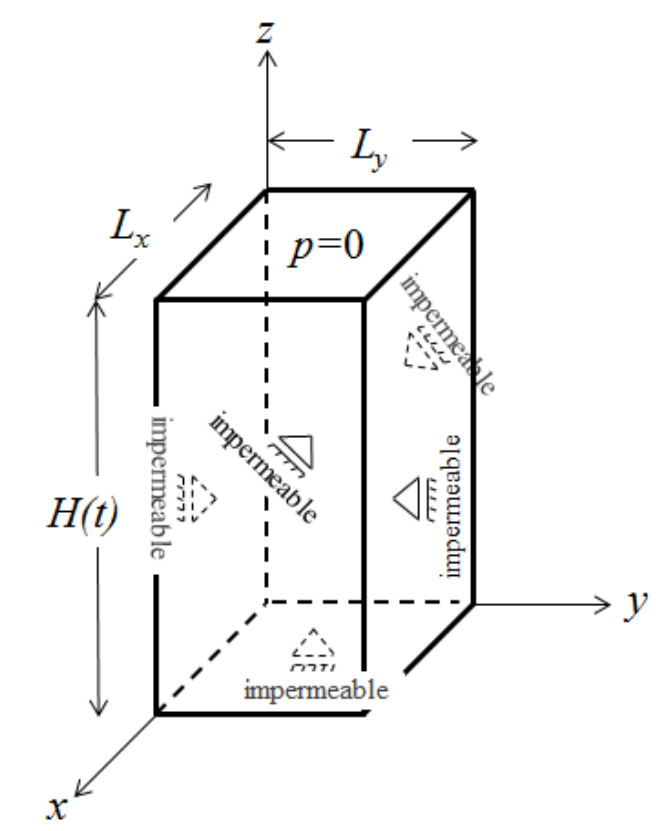

Figure 1. Poromechanical boundary conditions.

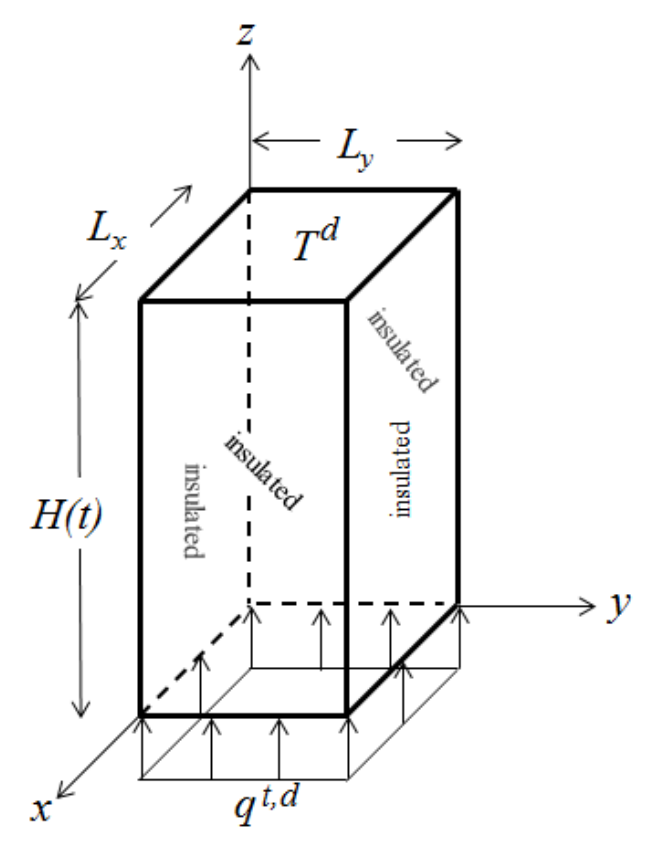

Figure 2. Thermal boundary conditions.

The fluid (water) saturating the connected pore network is considered incompressible with the following constant data: density $\rho^{f}=1000 \mathrm{~kg} / \mathrm{m}^{3}$, specific heat $c^{f}=4200 \mathrm{~J} / \mathrm{kg}^{\circ} \mathrm{C}$ and thermal conductivity $k^{t, f}=0.6 \mathrm{~W} / \mathrm{m}^{\circ} \mathrm{C}$. The viscosity coefficient of the pore fluid is given by (14).

The thermo-poro-mechanical parameters of the sandstone and shale models used on the numerical simulation are given in Table 1. Data are specified for initial porosity $\phi_{0}$ and reference temperature $T_{0}$ of each material. Regarding the permeability and thermal conductivity coefficients, only the values with respect to the vertical direction are provided as 
the numerical simulations are carried out under oedometric conditions. The fluid flow ability of the porous medium is characterized by the intrinsic permeability ù $=k^{f} \eta^{f}$.

The behavior of the constitutive models is analyzed through the evolution of a single material column for the sandstone in section 3.1 and shale in section 3.2. Section 3.3 presents two mixed lithology situations by varying the proportion of each deposited material along the stratigraphic sequences of the sedimentary basin. Section 3.4 illustrates a theoretical limit case on which chemo-mechanical compaction is totally inhibited by grain coating during basin evolution.

Table 1. Sandstone and shale model parameters.

\begin{tabular}{|c|c|c|c|}
\hline Parameter & Symbol & Sandstone & Shale \\
\hline Porosity $(\%)$ & $\varphi$ & 45 & 65 \\
\hline Density $\left(\mathrm{kg} / \mathrm{m}^{3}\right)$ & $\rho$ & 1880 & 1560 \\
\hline Young modulus (MPa) & $E$ & 5000 & 2500 \\
\hline Poisson's ratio & $v$ & 0.33 & 0.32 \\
\hline Biot coefficient & $b$ & 0.81 & 0.93 \\
\hline Biot modulus (MPa) & $M$ & 71326 & 119052 \\
\hline Thermal dilation coefficient of solid phase $\left(1 /{ }^{\circ} \mathrm{C}\right)$ & $\alpha^{s}$ & 0 & 0 \\
\hline Thermal dilation coefficient of pores $\left(1 /{ }^{\circ} \mathrm{C}\right)$ & $\alpha^{\phi}$ & 0 & 0 \\
\hline Intrinsic permeability $\left(\mathrm{m}^{2}\right)$ & ù & $10^{-14}$ & $10^{-18}$ \\
\hline Plastic critical state line & $M_{c s}$ & 1.2 & 1.2 \\
\hline Plastic hardening parameter $(\mathrm{MPa})$ & $p_{c}$ & 0.25 & 0.1 \\
\hline Plastic hardening law exponent & $m_{p}$ & 9.2 & 3 \\
\hline Viscoplastic critical state line & $M_{v p}$ & 1.2 & - \\
\hline Viscoplastic hardening parameter ( $\mathrm{MPa})$ & $p_{v p}^{s}$ & 1 & - \\
\hline Viscoplastic hardening law exponent & $m_{v p}$ & 2.6 & - \\
\hline Viscoplastic viscosity exponent & $n_{v p}$ & 0.001 & - \\
\hline Viscoplastic viscosity coefficient $(\mathrm{GPa} \times \mathrm{My})$ & $\eta_{v p}$ & 30 & - \\
\hline Activation energy $(\mathrm{kJ} / \mathrm{mol})$ & $E_{a}$ & 10 & - \\
\hline Specific heat $\left(\mathrm{J} / \mathrm{kg}^{\circ} \mathrm{C}\right)$ & $c$ & 1700 & 2300 \\
\hline Thermal conductivity coefficient $\left(\mathrm{W} / \mathrm{m}^{\circ} \mathrm{C}\right)$ & $k^{t}$ & 1.7 & 1.1 \\
\hline Volume heat generation $\left(\mathrm{W} / \mathrm{m}^{3}\right)$ & $r^{t}$ & 0 & 0 \\
\hline Reference temperature $\left({ }^{\circ} \mathrm{C}\right)$ & $T_{0}$ & 10 & 10 \\
\hline
\end{tabular}

\subsection{Sandstone model}

This section presents a pure sandstone model under drained conditions. The plastic and viscoplastic parameters of Table 1 were chosen to reproduce the porosity curve presented in Schneider and Hay (2001). These authors calibrated the porosity profile using data obtained 
from several wells of the Middle Jurassic Garn Formation from the Haltenbanken area of the Mid-Norwegian Continental Shelf. It is emphasized that the primarily purpose herein is not to simulate this specific formation, but to obtain realistic order of magnitude for the viscoplastic viscosity coefficient $\eta_{v p}$ and activation energy $E_{a}$ with respect to available data for further application in different synthetic cases. Fig. 3 illustrates the compaction history of the basin predicted by the present constitutive and computational model. The $8000 \mathrm{~m}$ of material deposited along $170 \mathrm{My}$ resulted in a sedimentary basin $5376 \mathrm{~m}$ thick, which corresponds to $32.8 \%$ of global deformation.

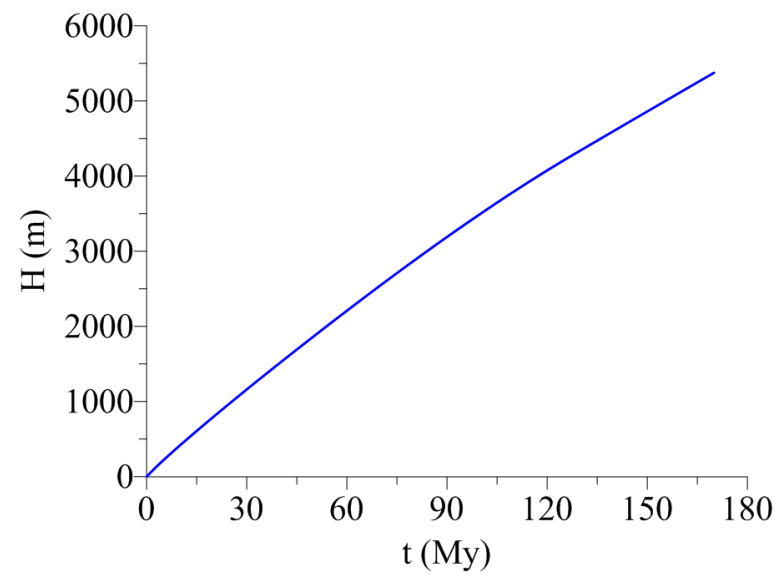

Figure 3. Compaction history (sandstone model).

To facilitate data interpretation and discussion, the basin profiles will be conveniently plotted considering the top of the basin located at $z=0$. The porosity profile is presented in Fig. 4 together with results from Schneider and Hay (2001) and Bjorkum et al. (1998). In the former work, the authors adopted a macroscopic visco-elasto-plastic model for the simulation of purely mechanical and chemo-mechanical compaction induced by intergranular pressuresolution in the Garn Formation. The latter work relies upon a clay-induced dissolution and local silica redistribution model to provide a set of porosity predictions for quartzose sandstones. It is noted that the porosity profile of Bjorkum et al. (1998) refers to a $170 \mathrm{My}$ basin with a temperature gradient of $35^{\circ} \mathrm{C} / \mathrm{km}$.

The first observation that arises from the comparison in Fig. 4 is the discrepancy regarding the porosity profiles predicted by the present sandstone model and that given in Schneider and Hay (2001) along the upper $1800 \mathrm{~m}$, where purely mechanical compaction is the dominating deformation process. As corroborated by the analysis of different porosity data from literature (Chuhan et al., 2002; Ramm, 1992; Sclater and Christie, 1980), this discrepancy can reasonably be attributed to the plastic hardening law (9) adopted in the modeling, which is likely not adequate to accurately represent the purely mechanical compaction of sandstones. Actually, such a hardening law leads to high porosity loss at low depths, which is mostly a characteristic of argillaceous sediments (Mondol et al., 2007). Although the introduction of exponent parameter $m_{p}$ yields more realistic porosity profiles along the basin upper layers than those presented in Brüch et al. (2018), the present analysis indicates that an improved plastic hardening law should be formulated for sandstones. However, the results derived from the current plastic hardening law are considered satisfactory enough within the scope of the present work, which primarily investigates the impact of chemical compaction on the evolution of the thermo-poro-mechanical state of the sedimentary basin. 
As regards the chemo-mechanical compaction prevailing at deeper layers, Fig. 4 shows that the viscoplastic modeling provides good fit with respect to the above mentioned works. The porosity value obtained at $2000 \mathrm{~m}$ is almost the same of the other curves, $27.7 \%$, decreasing to $9.6 \%$ at $4000 \mathrm{~m}$ and reaching $2.2 \%$ at the bottom of the basin. The porosity distribution in the deepest layers below $4300 \mathrm{~m}$ reveals an important issue for chemical compaction modeling at large scale: how to reasonably set a limit for chemically-induced deformation on the constitutive model. This is important in the context of basin modeling to avoid computational problems such as failure of the numerical process or either the prediction of negative porosities. In that respect, Schneider and Hay (2001) have for instance arbitrarily considered a residual porosity of $2 \%$ at which the numerical model does not allow further deformation of the porous material. In the present work, the magnitude of the mean effective stress required to trigger and maintain chemo-mechanical deformation depends on current porosity according to the viscoplastic hardening law (12), which automatically implies that unlimited high effective stresses are required for viscous deformation at low porosity values, as clearly illustrated by the model results in Fig. 4.

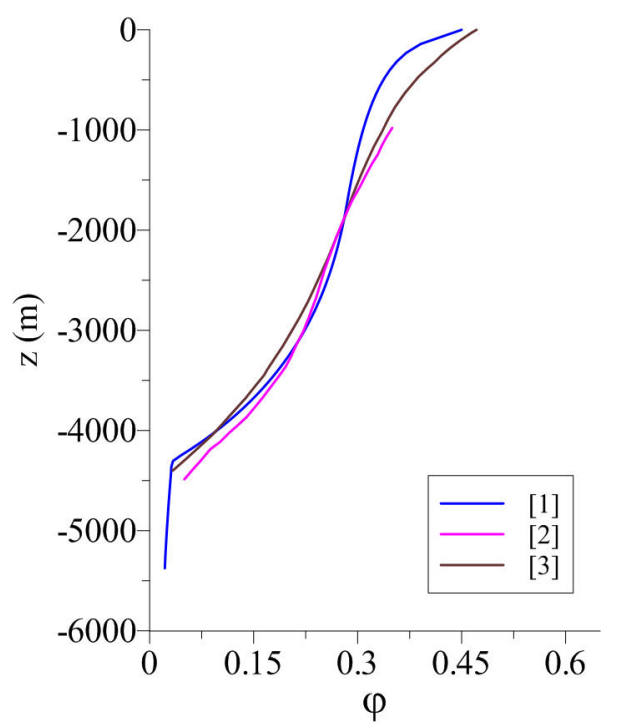

Figure 4. Porosity profiles: [1] sandstone model; [2] Bjorkum et al. (1998); [3] Schneider and Hay (2001).

Another interesting feature observed from Fig. 4 is the existence of an inflection point at approximately $1800 \mathrm{~m}$ depth. The concavity change appearing in all curves suggests that from this point chemo-mechanical compaction becomes the dominant deformation mechanism. To better understand this change of behavior with depth, the evolution on time of the first deposited (deepest) layer of the basin is investigated and some fundamental aspects of the constitutive model are illustrated. Fig. 5 presents the porosity evolution of the finite element located at the base of the geometry model. The porosity being calculated as a function of $J^{i r}=J^{p} J^{v p}$, it is possible to verify the contribution of purely mechanical and chemomechanical compaction processes on porosity change by drawing in Fig. 6 the time evolution of $J^{p}$ and $J^{v p}$. The evolution of temperature at the bottom of the basin is shown in Fig. 7, while that of the mean effective stress is shown in Fig. 8.

Starting at initial value of $45 \%$, the porosity rapidly decreases due to mechanical compaction resulting from increasing overburden, which leads under drained conditions to instantaneous increase of the local mean effective stress. The evolution of $J^{v p}$ shows that IPS slowly starts 
after $15 \mathrm{My}$ of sediment accretion with $33 \%$ of porosity, temperature around $30^{\circ} \mathrm{C}$ and mean effective stress of 4.2 $\mathrm{MPa}$. However, its contribution to porosity reduction remains nonsignificant along the next million years when compared to that of purely mechanical deformation, as illustrated in Fig. 6 where the $J^{p}$ curve continues to decrease with an important rate. After $30 \mathrm{My}$, when porosity reaches $30 \%$, temperature $50^{\circ} \mathrm{C}$ and mean effective stress $9 \mathrm{MPa}$, the chemo-mechanical compaction progressively becomes the dominant deformation process at the bottom of the basin. Concurrently, the contribution of purely mechanical compaction decreases until it completely stops at $50 \mathrm{My}$, presenting $\varphi \approx 28 \%, T \approx 75^{\circ} \mathrm{C}$ and $p^{\prime} \approx 15 \mathrm{MPa}$. The inflection point in the porosity curve shown in Fig. 5 reflects locally the same feature observed at the basin scale in the porosity profile of Fig. 4. After temperature exceeds $90^{\circ} \mathrm{C}$, the pressure-solution rate significantly increases, leading to rapid porosity reduction until the process is abruptly attenuated at $130 \mathrm{My}$ and corresponding $3.3 \%$ porosity. The bottom layer slowly continues to compact, finally reaching $2.2 \%$ of porosity after $170 \mathrm{My}$ of basin history. It is interesting to observe in Fig. 6 that 115 My of sediment deposition were necessary for the $J^{v p}$ and $J^{p}$ curves to intersect, which means that at this stage the contribution of mechanical and chemo-mechanical compaction to porosity reduction turn equivalent. The maximum temperature and mean effective stress reached at the bottom of the basin are respectively $174^{\circ} \mathrm{C}$ and $50 \mathrm{MPa}$.

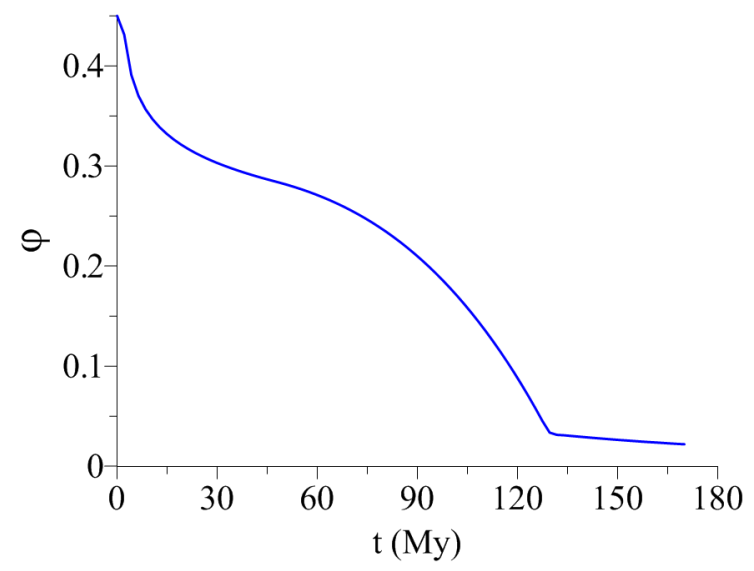

Figure 5. Porosity evolution at the bottom of the basin (sandstone model).

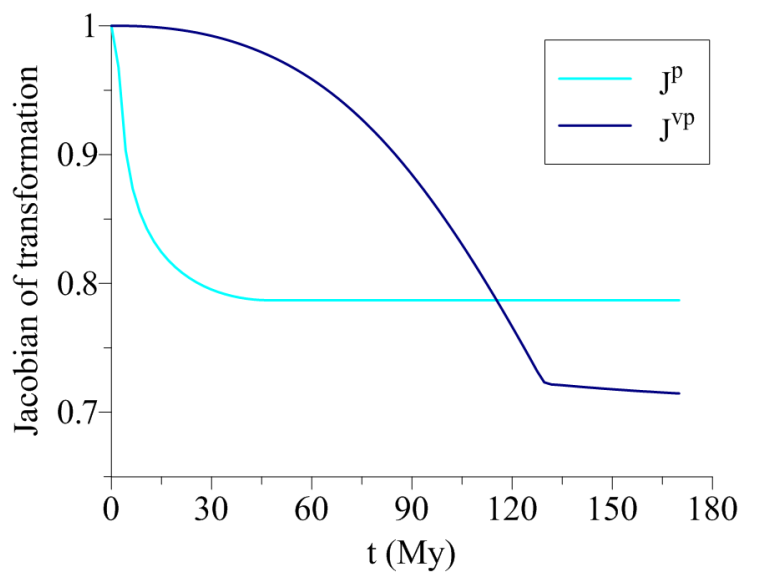

Figure 6. Evolution of the Jacobian of plastic and viscoplastic transformation at the bottom of the basin (sandstone model). 


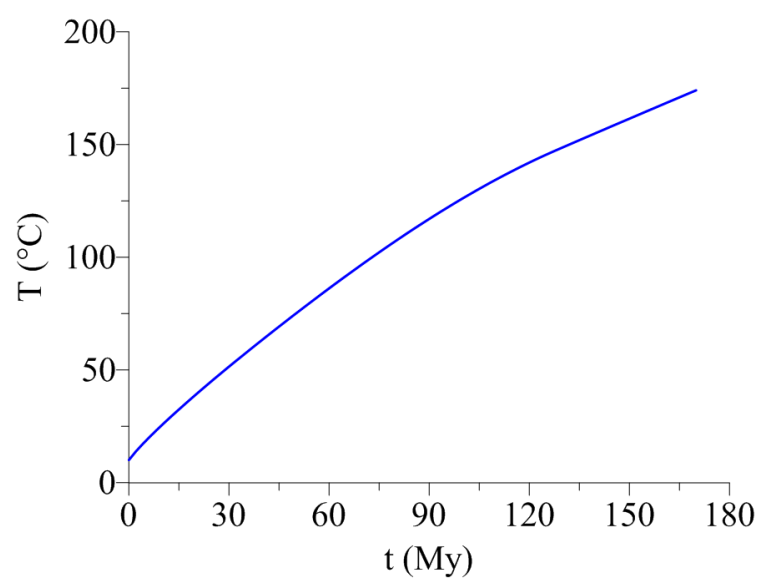

Figure 7. Temperature evolution at the bottom of the basin (sandstone model).

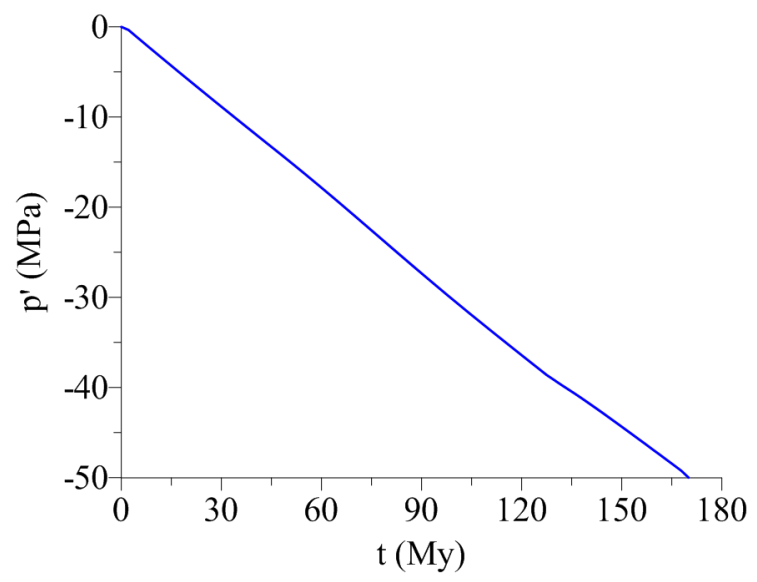

Figure 8. Mean effective stress evolution at the bottom of the basin (sandstone model).

The same interpretation regarding the purely mechanical and chemo-mechanical specific contributions to porosity change can be made at basin scale by analyzing the profiles of $J^{p}$ and $J^{v p}$ depicted in Fig. 9, together with the temperature profile of Fig. 10 and the mean effective stress curve of Fig. 11. From top to bottom, the curves indicate that chemomechanical contribution is negligible along the first $1000 \mathrm{~m}$, followed by a transition zone where both phenomena simultaneously occur and mechanical compaction rate decreases as a consequence of grain rearrangement, quartz dissolution and cementation. Beyond depth of $1800 \mathrm{~m}$ where $\varphi \approx 28 \%, T \approx 75^{\circ} \mathrm{C}$ and $p^{\prime} \approx 15 \mathrm{MPa}$, there is no further purely mechanical deformation. The chemical process accelerates with depth as effective stress and temperatures increase and decelerates after $4300 \mathrm{~m}$ as a consequence of the hardening law. As regards the temperature distribution, it can be observed from Fig. 10 that the temperature gradient $\partial T / \partial z$ is not constant, with a mean value $\Delta T / \Delta z$ along the basin thickness equal to $30.5^{\circ} \mathrm{C} / \mathrm{km}$.

The obtained results for the sandstone model are in accordance with the literature description presented throughout this work regarding the depths at which each phenomenon predominates, their contribution to porosity reduction and the associated temperatures and effective stresses. However, the high permeability of the sandstone material led to drained behavior (i.e., no fluid overpressures) even at low porosity layers, which is not the case of the Garn Formation taken as reference for porosity distribution. This resulted in very high 
effective stresses as shown in Fig. 11. The choice of considering such a high pemeability for the sandstone material and to calibrate the viscoplastic parameters $\eta_{v p}$ and $E_{a}$ under drained conditions has been made with the purpose to investigate in section 3.3 the impact of overpressure development on IPS mechanism and its consequences on basin evolution by mixing high permeability sandstone and low permeability shale layers.

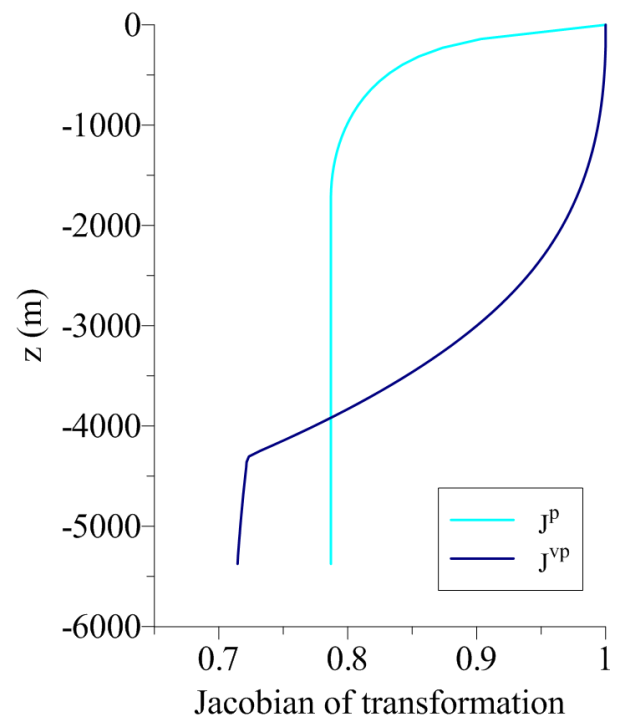

Figure 9. Profiles of the Jacobian of plastic and viscoplastic transformation (sandstone model).

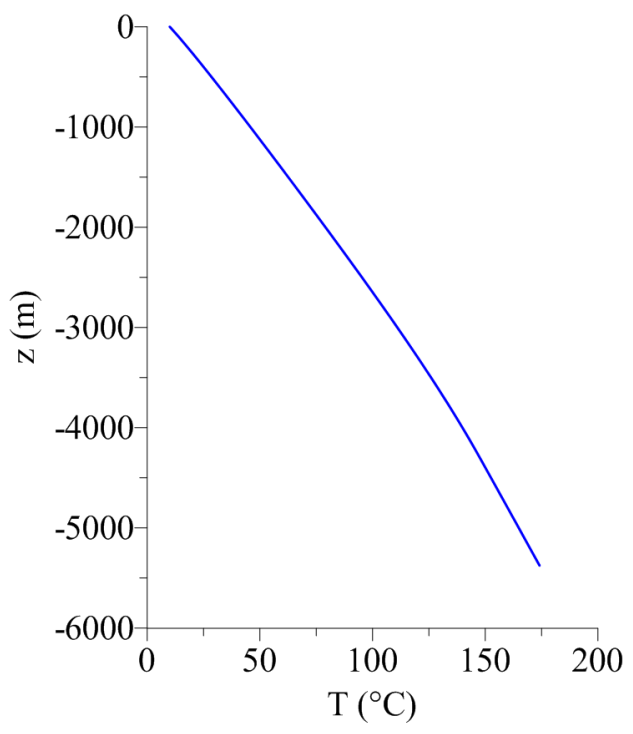

Figure 10. Temperature profile (sandstone model). 


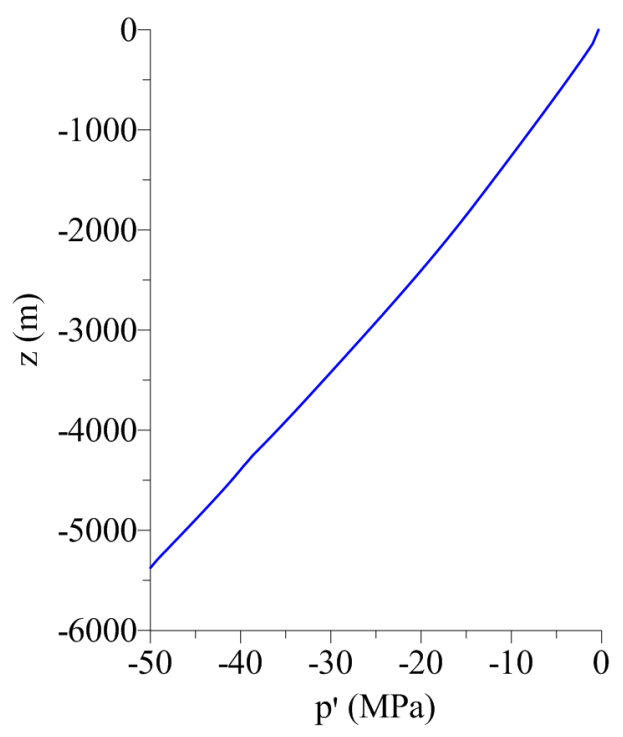

Figure 11. Mean effective stress profile (sandstone model).

\subsection{Shale model}

This section is devoted to the numerical simulation of thermo-poro-mechanical behavior of sedimentary basins formed by shale-like rocks. For sake of simplicity, chemo-mechanical compaction is not considered for this material although shale formations may present important chemically-induced deformation (Goulty et al., 2016; Kalani et al., 2015). The plastic parameters were chosen to fit the general trend of the porosity-depth compilation presented by Mondol et al. (2007) for several shales and argillaceous sediments from different parts of the world.

The compaction history predicted by the numerical model is presented in Fig. 12. After 8000 $\mathrm{m}$ of material deposition with a constant rate of $47 \mathrm{~m} / \mathrm{My}$, the final thickness of the basin is $3420 \mathrm{~m}$, which corresponds to $57.2 \%$ overall deformation. This compaction level is qualitatively consistent with the levels reported by Hamilton (1959) who concluded, at the basis of geochemical analysis of several sedimentary basins data, that more than $5000 \mathrm{~m}$ of clay sediments would be necessary to form a basin $2 \mathrm{~km}$ thick, representing an overall deformation of about $60 \%$. The porosity-depth profile presented in Fig. 13 is consistent with argillaceous sediments data (Nooraiepour et al., 2017), thus indicating that the proposed hardening law (9) proves relevant as regards the modeling of clays behaviour: the initial porosity value of $65 \%$ decreases to $28.6 \%$ at $500 \mathrm{~m}$ depth, $20.5 \%$ at $1000 \mathrm{~m}$ and $13 \%$ at 2000 $\mathrm{m}$. The porosity predicted at the bottom of the basin from the numerical simulation reaches $7.2 \%$. 


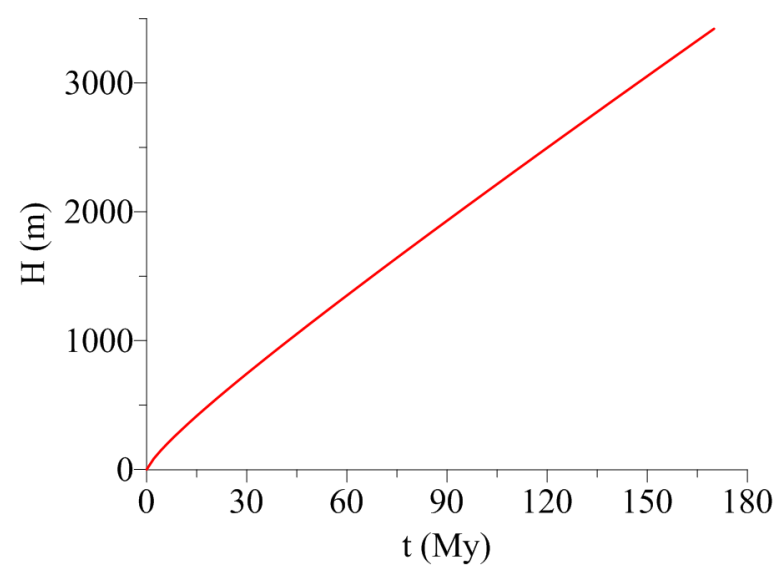

Figure 12. Compaction history (shale model).

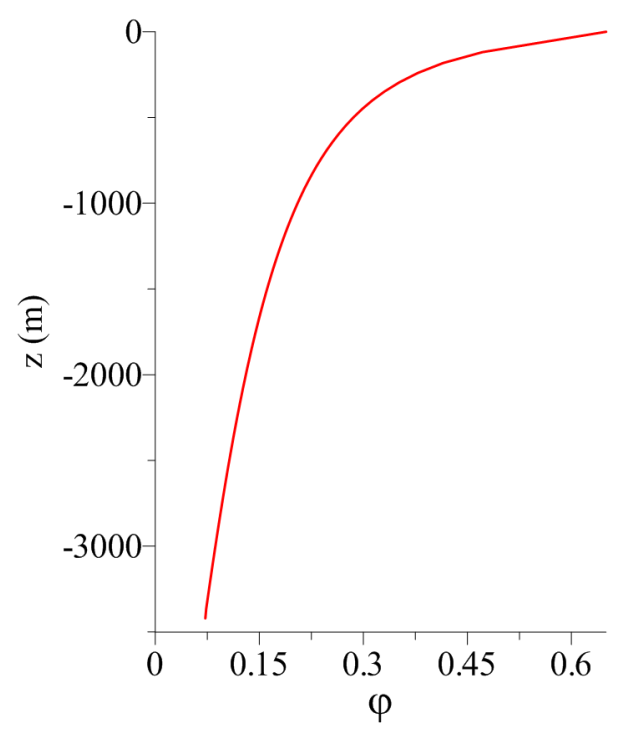

Figure 13. Porosity profile (shale model).

The temperature distribution of the shale column is shown in Fig. 14. The maximum value at the bottom layer is $134^{\circ} \mathrm{C}$, the mean value of geothermal gradient $\Delta T / \Delta z$ in the basin thickness being equal to $36.5^{\circ} \mathrm{C} / \mathrm{km}$. The temperature variation is higher for the shale formation than for the sandstone case. Keeping in mind that similar thermal boundary conditions were prescribed in both cases (top temperature and bottom heat flow), this result could be naturally expected because shale rocks are commonly less conductive than sandstones (Gallagher et al., 1997). It is noted, however, that the temperature reached at the bottom of the basin reveals lower for shale than sandstone since the resulting basin thickness is significantly smaller. 


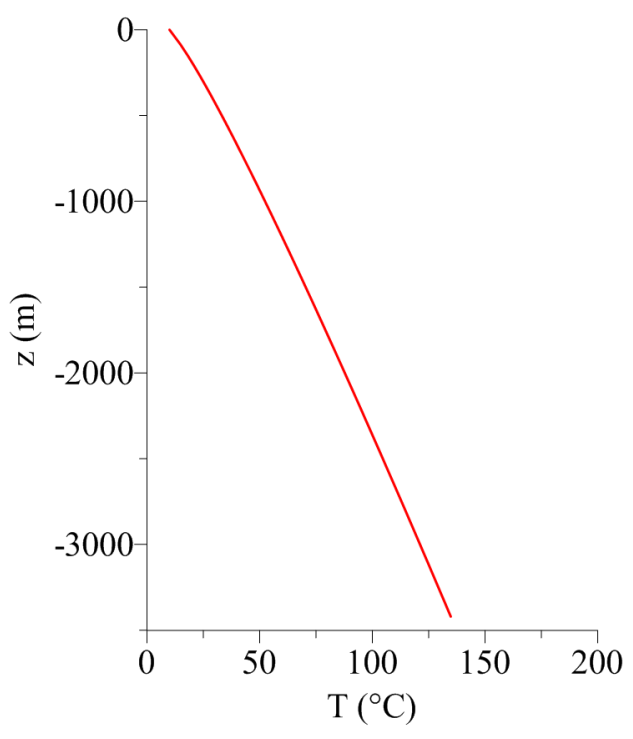

Figure 14. Temperature profile (shale model).

The mean effective stress profile is illustrated in Fig. 15, whereas the overpressure profile is depicted in Fig. 16. It can be observed that the effective stress values are significantly lower than those mobilized in the sandstone model. It is actually a straightforward consequence of the overpressure development associated with the low permeability of the material model. The maximum values reached for mean effective stress and overpressure at the bottom of the basin are respectively $20.2 \mathrm{MPa}$ and $17.7 \mathrm{MPa}$. The predicted porosity change, temperature distribution as well as magnitude of the mean effective stress and pore fluid pressure are consistent with available data from North Sea formations (Daniel, 2001; Goulty and Sargent, 2016). Overall, the numerical results obtained within the framework of oedometric deformation indicate that the constitutive material modeling captures the essential features described in the above-cited literature regarding the evolution of fundamental geological parameters, thus providing validation of the shale constitutive model that will be used in the composite lithology analyzed in next section.

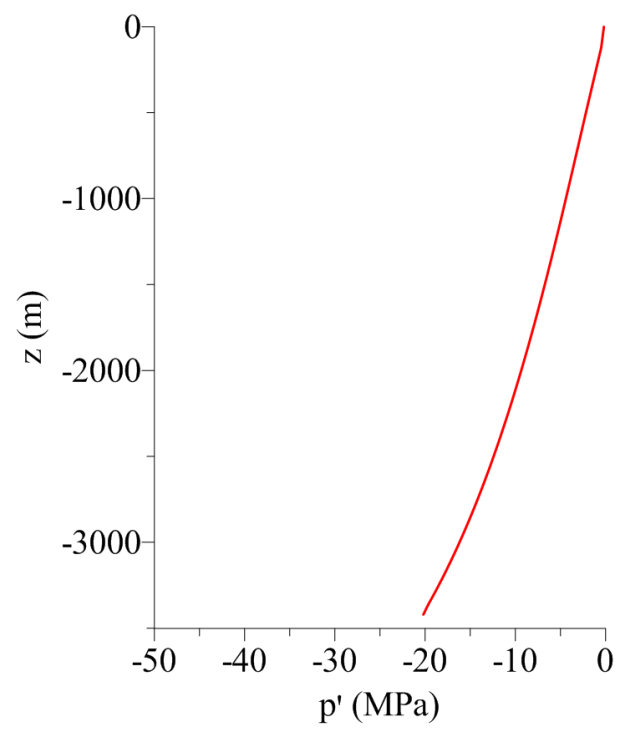

Figure 15. Mean effective stress profile (shale model). 


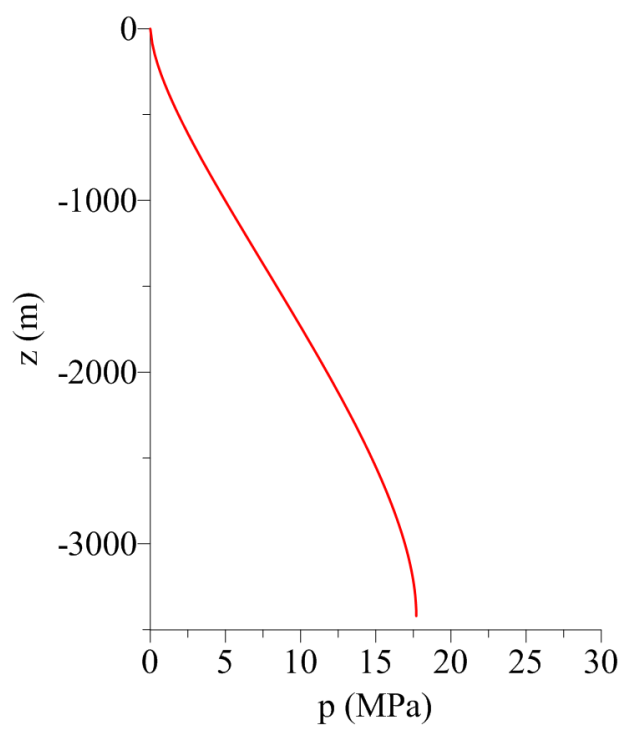

Figure 16. Overpressure profile (shale model).

\subsection{Mixed sandstone and shale models}

The sandstone and shale models defined in the previous sections are used to investigate the connection between material permeability and the evolution of thermo-poro-mechanical fields, such as the effective stress distribution, pore fluid pressure and chemo-mechanical compaction induced by intergranular pressure-solution. For this purpose, two composite lithologies shall be considered. In both cases, the basin is formed from the continuous deposition of $8000 \mathrm{~m}$ sediment material, according to a predefined stratigraphic distribution that is repeated every $1000 \mathrm{~m}$. The models are identified by their sandstone/shale proportion. The so-called $80 / 20$ model has $80 \%$ of sandstone and $20 \%$ of shale with the following configuration: every $1000 \mathrm{~m}$ of material comprises $800 \mathrm{~m}$ of sandstone followed by $200 \mathrm{~m}$ of shale. The same is done for the $40 / 60$ model: for every $1000 \mathrm{~m}$ of sediments, $400 \mathrm{~m}$ of sandstone are covered by $600 \mathrm{~m}$ of shale, resulting in eight sandstone compartments separated by eight shale cap rocks. Similarly to the situations analyzed in sections 3.1 and 3.2, the basin is formed along $170 \mathrm{Ma}$ with constant sediment accumulation rate.

The compaction histories associated with the two material configurations are given in Fig. 17. The final thicknesses of the basins are $5235 \mathrm{~m}$ and $4409 \mathrm{~m}$ for the 80/20 and 40/60, respectively, which correspond to $34.5 \%$ and $44.9 \%$ overall deformation. As it could be expected, these deformation levels fall within the range $32.8 \%-57.2 \%$ obtained for the sandstone and shale models. For comparison purposes, the basin profiles will be conveniently presented by normalizing the depth (z-coordinate) in each lithography configuration by the corresponding basin thickness that is reached at the end of the numerical simulation. 


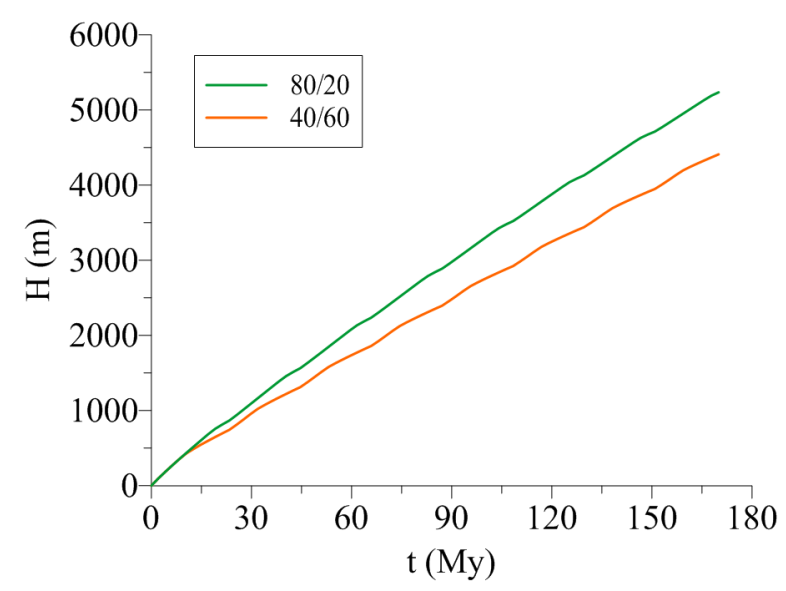

Figure 17. Compaction histories ( $80 / 20$ and $40 / 60$ models).

It is possible to distinguish in Fig. 18, displaying the porosity profiles related to each model, the eight stratigraphic sequences of high porosity sandstones and low porosity shale layers. The results indicate more porosity preservation in the sandstone compartments covered by higher amounts of shale material, suggesting that the overpressure generation associated with these low permeability layers restrained both mechanical compaction of the top layers and chemical compaction at greater depths. The porosity in the deepest sandstone layer is $5.1 \%$ for the $80 / 20$ model and $9.1 \%$ for the $40 / 60$ basin.

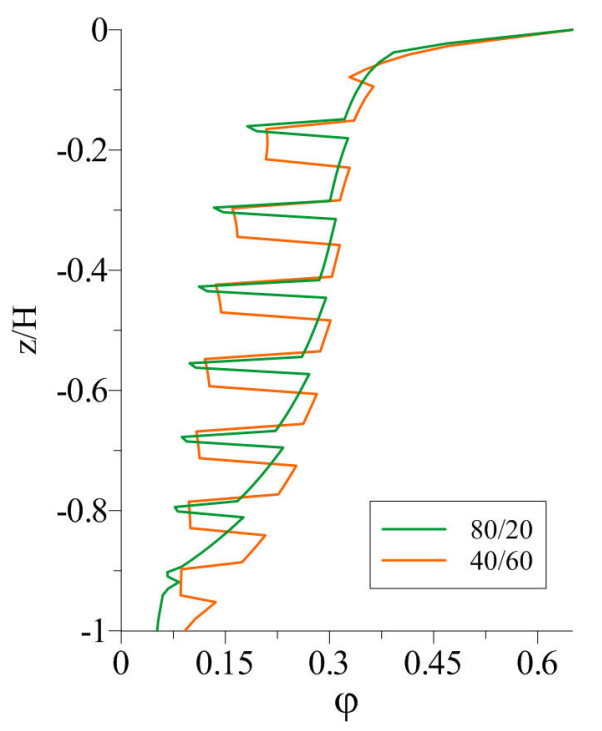

Figure 18. Porosity profiles (80/20 and 40/60 models).

As regards the connection between the porosity and thermal evolution in the basin, the temperature distributions shown in Fig. 19 suggest lower porosities associated with higher temperatures for the 80/20 model. This feature of the macroscopic behavior can be explained as follows: heat modifies the fluid viscosity and quartz kinetics, accelerating overpressure dissipation and mineral dissolution, thus increasing the rates of mechanical and chemical deformations. The maximum temperatures that are reached at the basin bottom for the 80/20 and $40 / 60$ models are respectively $180.8^{\circ} \mathrm{C}$ and $162.6^{\circ} \mathrm{C}$, and the corresponding average geothermal gradients are $32.6^{\circ} \mathrm{C} / \mathrm{km}$ and $34.6^{\circ} \mathrm{C} / \mathrm{km}$. It is interesting to note that, although the 
$80 / 20$ model resulted in a smaller column when compared to the sandstone case, the less conductive shale layers led to higher temperature at the bottom of the composite basin.

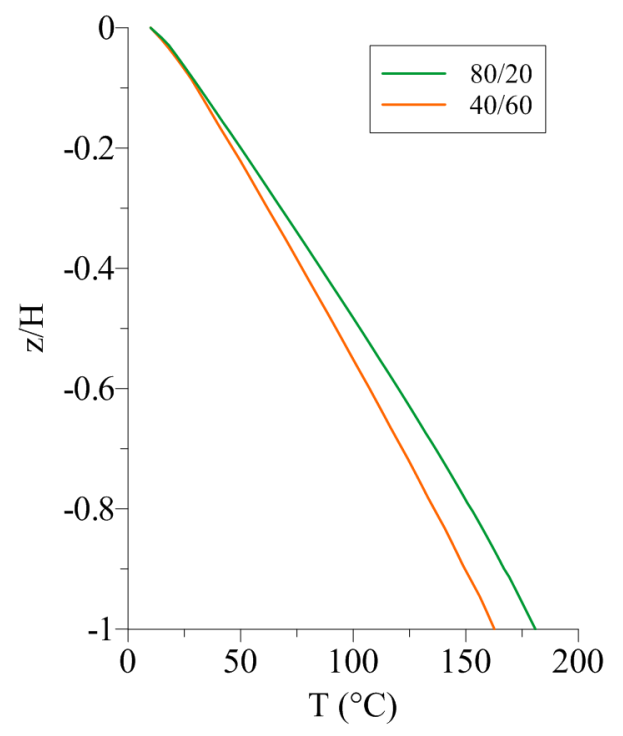

Figure 19. Temperature profiles ( $80 / 20$ and $40 / 60$ models).

The mean effective stress and overpressure profiles are shown in Fig. 20 and Fig. 21, respectively. As the effective stress depends on both the lithostatic stress and pore fluid pressure, it is expected, and corroborated by Fig. 20, that model 80/20 will exhibit higher effective stresses since it contains larger quantities of sandstone (characterized by higher density and permeability) and less of shale component (having lower density and permeability values). Regarding the pore pressure distribution, it is expected that model 40/60, with higher amount of low permeability shale component, would present along all normalized depths significantly higher overpressures than $80 / 20$ model. This feature is actually not observed in all sandstone compartments. Referring to Fig. 21 and analyzing from bottom to top, the first compartment of the 40/60 model presents higher overpressures than for the 80/20 model, followed by three compartments where overpressures are almost the same, presenting once again higher values in the last four compartments.

The results illustrated so far are consistent with the fact that a sedimentary basin with higher permeability, temperature and lithostatic stress would generally exhibit lower porosity sandstone formations and higher effective stresses. Nevertheless, it may appear at first glance intriguing that both models resulted in very similar overpressure distributions along the deep layers, while model 40/60 has three times the amount of shale material of the 80/20 one. Interpretation and explanation of predicted fluid pressure distributions in light of the multiple coupled processes involved in the basin formation is only possible by analyzing the geological history of the numerical models. 


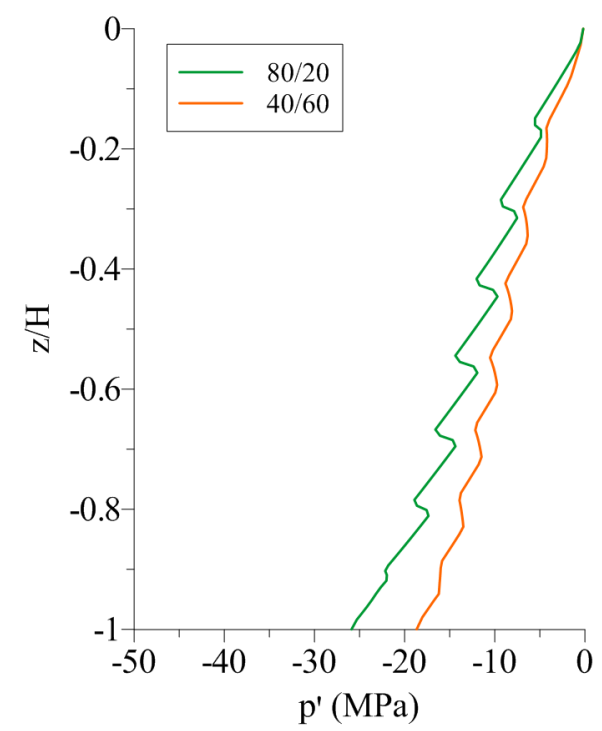

Figure 20. Mean effective stress profiles (80/20 and 40/60 models).

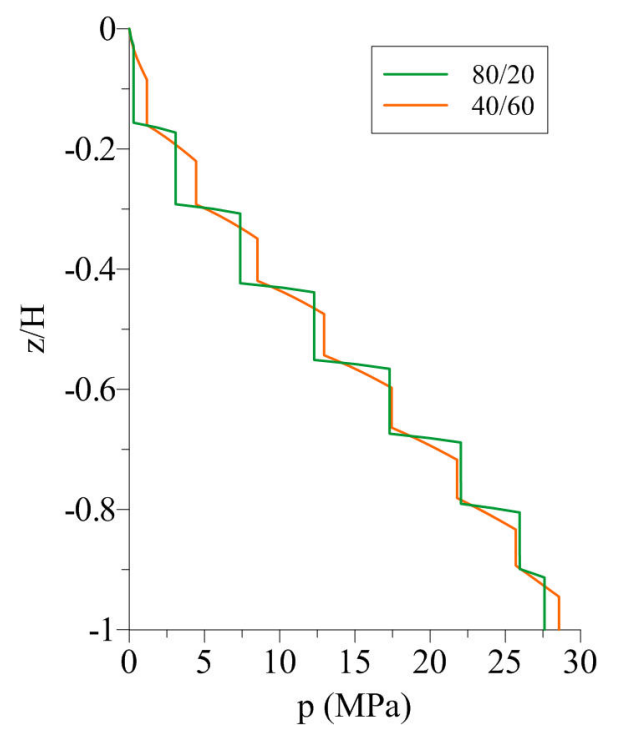

Figure 21. Overpressure profiles (80/20 and 40/60 models).

Following the same procedure described in section 3.1, the evolution on time of the finite element located at the base of the geometry model is investigated. Fig. 22 to Fig. 25 respectively show the porosity, temperature, mean effective stress and overpressure values at the bottom of the basin for both models. During the first millions of years the overpressure development associated with overburden is not significant, leading for both models to similar effective stress and porosity evolutions resulting from purely mechanical compaction. As overpressure evolves with different rates according to the amount of low permeability shale material in each basin model, the lower effective stress evolution of model 40/60 leads to lower porosity reduction in comparison to model 80/20. However, the difference observed on the porosity curves remains relatively constant until approximately $60 \mathrm{My}$, age after which chemo-mechanical compaction starts to predominate, inducing higher porosity reduction in the $80 / 20$ model as a consequence of increasing difference in effective stress and temperature. 
After $150 \mathrm{My}$, the rate of deformation induced by pressure-solution diminishes for model $80 / 20$ while for model $40 / 60$ it continues to increase until the end of the simulation.

The overpressure development along the basin layers is a consequence of overburden and subsequent chemical compaction of the sandstone material through intergranular pressuresolution. The resulting fluid overpressure accumulates in the sandstone compartments because purely mechanical deformation in the overlying shale layers progressively reduces the permeability of the cap rocks, thus hindering overpressure dissipation of the system. The figures indicate that the early overpressure development due to progressive overburden in the $40 / 60$ model resulted in low effective stresses, which in turn leads to lower rates of porosity change over time. On the other hand, the higher permeability of the 80/20 model led to higher effective stresses, increasing the rate of chemo-mechanical compaction, which resulted in important overpressure generation at later stages of the basin.

It is interesting to note that the evolution of effective stresses and temperature accelerated pressure-solution deformation at the base of the model 80/20 after $60 \mathrm{My}$, increasing the rate of overpressure development until the latter exceeds the values predicted in the 40/60 model at $120 \mathrm{My}$ and then slows down after $150 \mathrm{My}$. In the last range of sediment accretion process, that is between $150 \mathrm{My}$ and $170 \mathrm{My}$, the overpressure generation rate becomes more important in the model 40/60, resulting in higher values at $170 \mathrm{My}$. A similar behavior was presented by Wangen (2000), concluding that overpressure build-up associated with porosity reduction through quartz cementation rapidly accelerates with increasing kinetics rates but reaches its maximum at low porosities as the potential for fluid expulsion is exhausted. This explains the overpressure profiles of Fig. 21, where the sandstone formations dominated by purely mechanical compaction exhibited higher values for the 40/60 model, whereas those undergoing important chemical compaction presented nearly the same values for both cases.

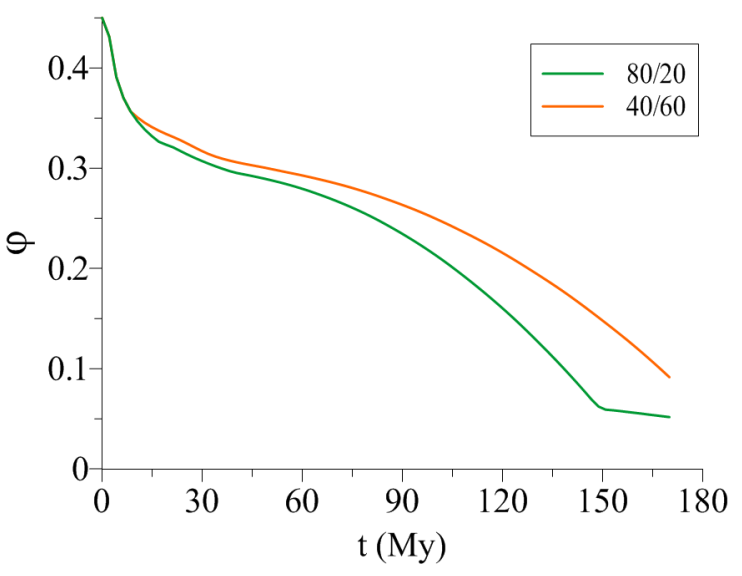

Figure 22. Porosity evolution at the bottom of the basin (80/20 and 40/60 models). 


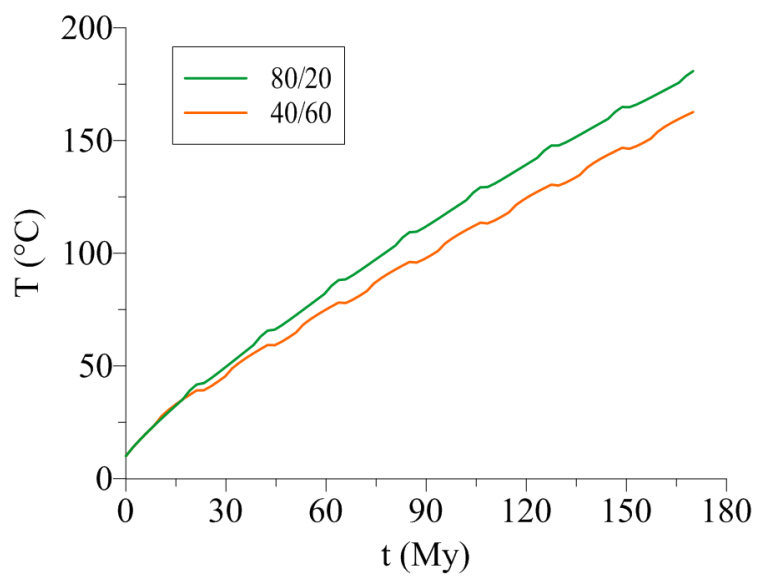

Figure 23. Temperature evolution at the bottom of the basin (80/20 and 40/60 models).

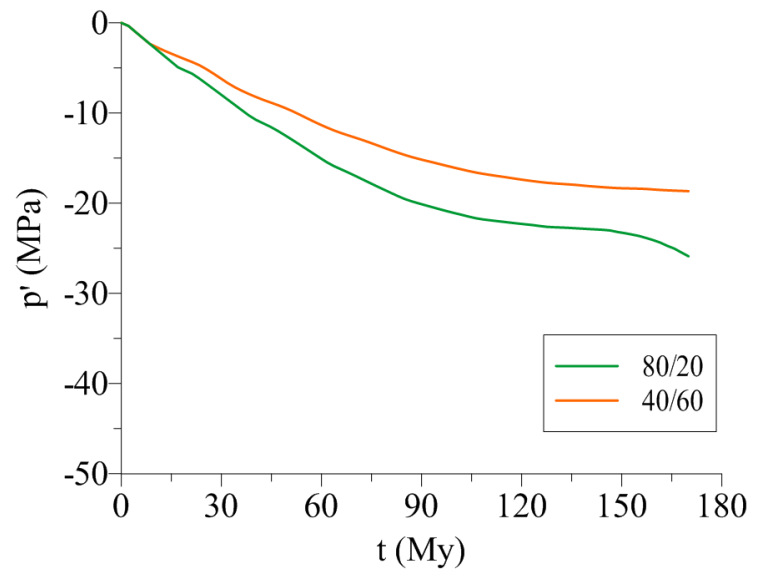

Figure 24. Mean effective stress evolution at the bottom of the basin (80/20 and 40/60 models).

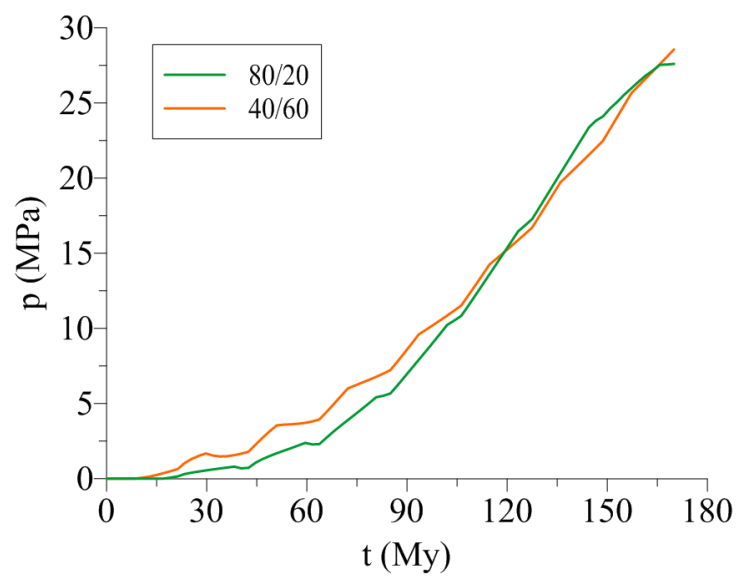

Figure 25. Overpressure evolution at the bottom of the basin ( $80 / 20$ and 40/60 models). 


\subsection{Pressure-solution inhibition}

The three main causes of pressure-solution inhibition and consequent porosity preservation in sandstones are early overpressure development, hydrocarbon emplacement and grain coating (Stricker and Jones, 2016; Bloch et al., 2002). The first driving mechanism has been discussed through the numerical examples presented in section 3.3. Regarding the second one, it is known that hydrocarbons may hinder pressure-solution but there still exist some controversy about its effectiveness with respect to significant porosity preservation since in general sandstone reservoirs are predominantly water wet (Bjorkum et al., 1998; Osborne and Swarbrick, 1999; Ramm, 1992). The third cause of pressure-solution inhibition is recognized to be the most effective mechanism of porosity preservation in deeply buried sandstone reservoirs, where the presence of clays such as illite and chlorite reduce the available surface of grains for authigenic quartz cementation (Wooldridge et al., 2017; Dowey et al., 2012).

Aiming to illustrate this phenomenon, a numerical simulation of the 80/20 model described in section 3.3 will be reproduced in the limit situation where IPS is totally inhibited. The socalled $80 / 20[\mathrm{~b}]$ model presents exactly the same boundary conditions and depositional history as before, the only difference lying in the deactivation of the viscoplastic behavior in the constitutive model presented in Table 1 for the sandstone material, so that only purely mechanical compaction is allowed to take place in the sedimentary basin.

The compaction history of the $80 / 20$ [b] model is presented in Fig. 26 together with the obtained results from the original 80/20 model. The present simulation resulted in a basin $5406 \mathrm{~m}$ thick, slightly thicker than the previous case which resulted in $5235 \mathrm{~m}$. The overall deformation is $32.4 \%$ against $34.5 \%$ of section 3.3 . Differently from the previous section, where the basin profiles were presented with normalized depths in order to investigate the evolution of different thermo-poro-mechanical aspects within corresponding sandstone compartments of each case, the results will be presented hereafter by providing the total depth of the basins, allowing to establish direct comparisons between the two configurations.

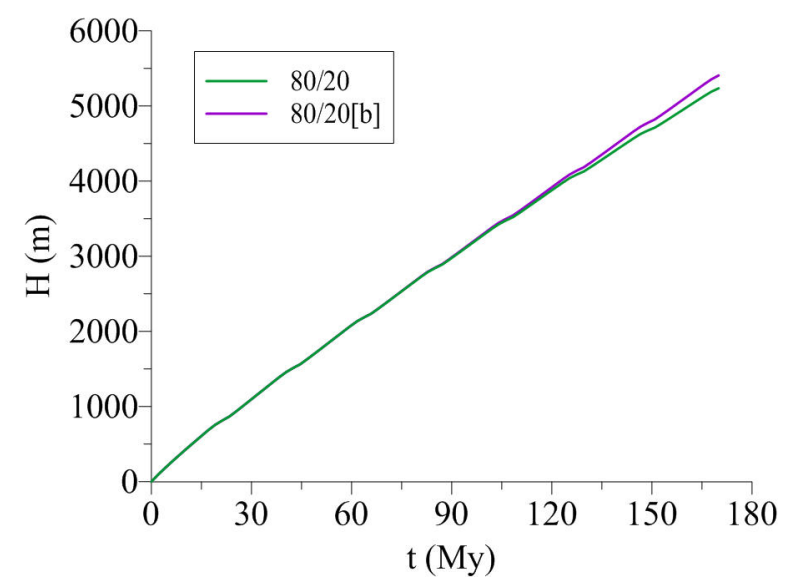

Figure 26. Compaction histories (80/20 and $80 / 20[b]$ models).

The porosity profiles are given in Fig. 27, where it can be seen that the upper part of the basins controlled by purely mechanical compaction presented nearly the same porosity distribution down to $2500 \mathrm{~m}$ depth. In contrast, the inhibition of IPS compaction in model $80 / 20$ [b] led to important porosity preservation beyond this point. While model 80/20 submitted to chemo-mechanical compaction provided porosity of $22.2 \%$ at $3500 \mathrm{~m}$ (base of the fourth compartment from bottom to top), $16.7 \%$ at $4100 \mathrm{~m}$ (base of the third compartment) and $8.7 \%$ at $4700 \mathrm{~m}$ (base of the second compartment), the corresponding 
porosities for the $80 / 20$ [b] model are $26.8 \%, 26.2 \%$ and $25.6 \%$. The porosity reached at the bottom of the basin is $5.1 \%$ for the first model, whereas it is $25 \%$ for the latter. It is interesting to note that the shale layers between each sandstone compartment presented lower porosity values when IPS was inhibited. As previously mentioned in section 3.3, this feature may be attributed to higher effective stresses since IPS compaction leads to overpressure build-up along the basin.

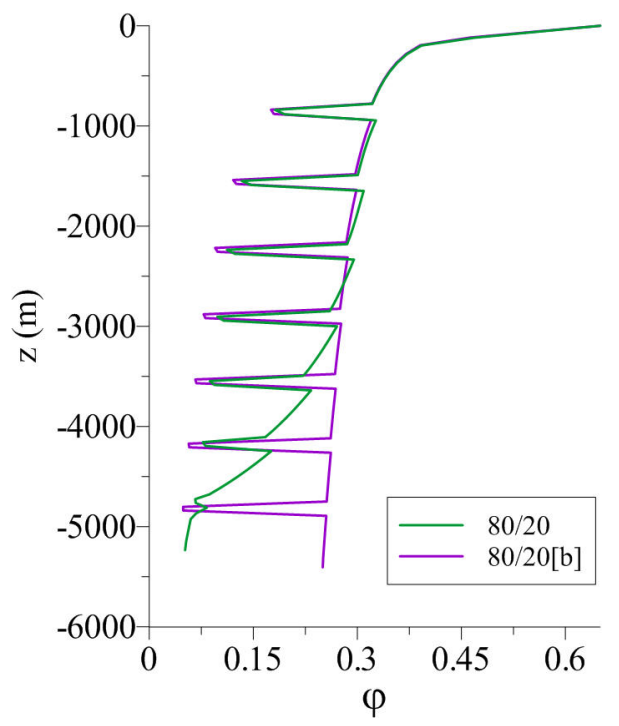

Figure 27. Porosity profiles (80/20 and 80/20[b] models).

The profiles of Fig. 28 show that both cases resulted in similar temperature distributions through depth, with some differences at the lower part of the basins: as minerals have higher thermal conductivity than water, the lower porosity sandstone compartments of model 80/20 turned out more conductive than the $80 / 20$ [b] ones, resulting in lower temperatures between $4200 \mathrm{~m}$ and $5235 \mathrm{~m}$ (base of the 80/20 model). The maximum temperatures reached at the bottom of the $80 / 20$ and $80 / 20[\mathrm{~b}]$ models are respectively $180.8^{\circ} \mathrm{C}$ and $192.2^{\circ} \mathrm{C}$ with corresponding average geothermal gradients equal to $32.6^{\circ} \mathrm{C} / \mathrm{km}$ and $33.7^{\circ} \mathrm{C} / \mathrm{km}$.

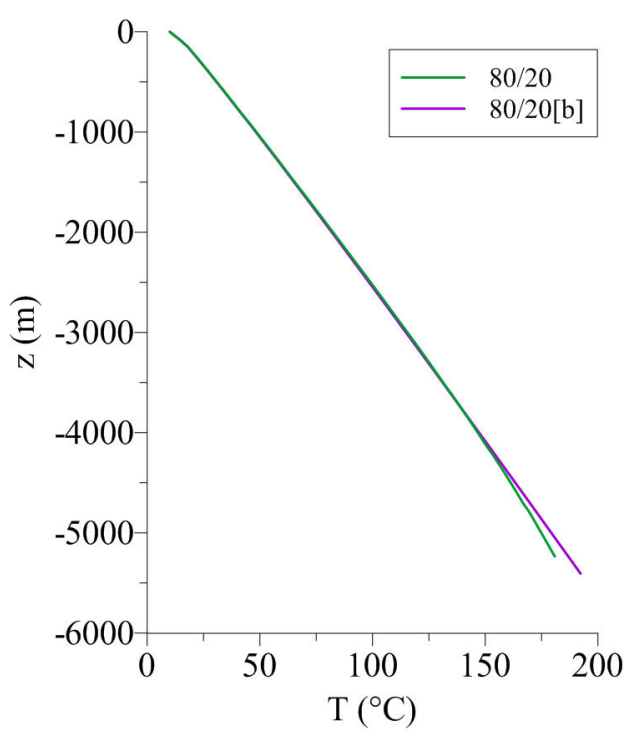

Figure 28. Temperature profiles (80/20 and 80/20[b] models). 
The overpressure build-up resulting from chemo-mechanical compaction and the associated effective stress relaxation can be quantitatively analyzed from Fig. 29 and Fig. 30, which respectively display the mean effective stress and overpressure profiles. The results show that the inhibition of IPS compaction in model 80/20[b] resulted in significant lower overpressures and consequently higher effective stresses, which provides once again explanation for the lower porosity shale layers predicted from this model and depicted in Fig. 27.

Regarding the lower four sandstone compartments where IPS compaction prevailed in model $80 / 20$ of section 3.3, the overpressure values from bottom to top are 27.6, 26, 22 and 17.3 $\mathrm{MPa}$, whilst those of the 80/20[b] model are 16, 14.7, 12.6 and $10 \mathrm{MPa}$, corresponding respectively to $72.5 \%, 76.8 \%, 74.6 \%$ and $73 \%$ of overpressure increase due to chemomechanical compaction. It is however important to note that even though the porosity distributions of both cases were nearly the same along the top four sandstone compartments where purely mechanical compaction dominated, the effective stress and overpressure distributions were in fact also affected by the evolution of the lower part of the basin submitted to pressure-solution. From bottom to top, the overpressure values at these layers are 12.3, 7.4, 3.1 and 0.2 MPa for model 80/20, and 7.2, 4.4, 1.9 and 0.2 MPa for model 80/20[b], which correspond respectively to $70.8 \%, 68.2 \%$ and $41.9 \%$ of overpressure increase for the first three compartments. This is actually an important feature in basin modeling and understanding of the mechanical evolution of basin systems as it indicates that important chemically-induced compaction at deep layers may affect the thermo-poro-mechanical behavior of the top layers. The associated consequences can be even more important in the case of seal rocks fracturing and reservoirs connection, impacting on overpressure distribution and fluid migration.

Keeping in mind that both models have exactly the same boundary conditions and depositional (overburden) history, the definition of effective stress indicates that its value decreases as a consequence of overpressure build-up, which explains the differences between the mean effective stress profiles of Fig. 29. It is interesting to observe that, although the mean effective stress of the $80 / 20$ [b] model significantly increases with depth, it does not translate into important porosity decrease as purely mechanical compaction approaches its limit between 2000 to $3000 \mathrm{~m}$ depth, for which the corresponding values are $p^{\prime}=12.9 \mathrm{MPa}$ and $\varphi=28.8 \%$ at $2000 \mathrm{~m}$, and $p^{\prime}=17.5 \mathrm{MPa}$ and $\varphi=27.6 \%$ at $3000 \mathrm{~m}$. The bottom of the basin presents $33.4 \mathrm{MPa}$ of mean effective stress and $25 \%$ of porosity for the $80 / 20$ [b] model in contrast to $25.9 \mathrm{MPa}$ and $5.1 \%$ for model $80 / 20$ accounting for chemo-mechanical compaction. 


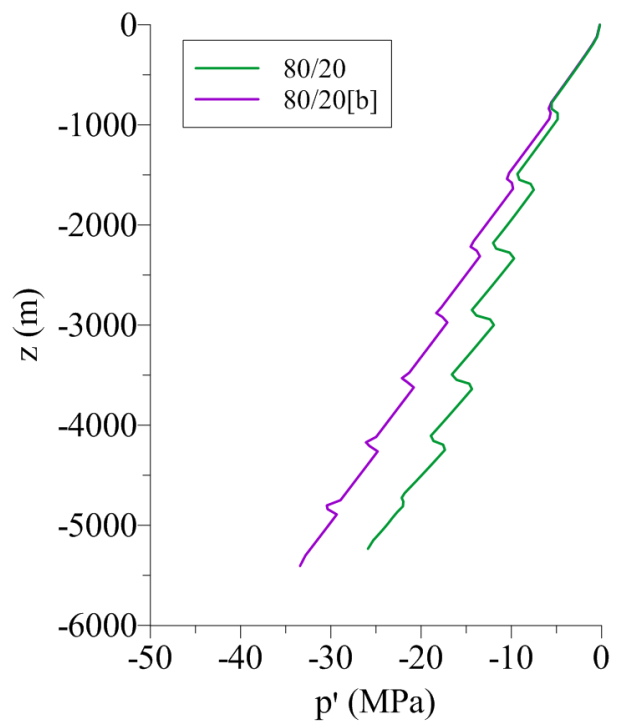

Figure 29. Mean effective stress profiles $(80 / 20$ and $80 / 20[b]$ models).

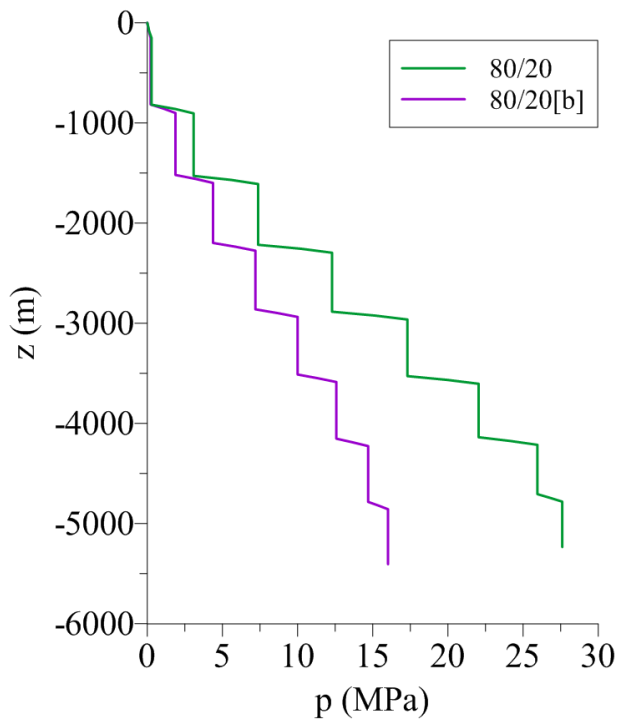

Figure 30. Overpressure profiles $(80 / 20$ and $80 / 20[b]$ models). 


\section{CONCLUSIONS}

Mechanisms of overpressure generation associated with chemo-mechanical compaction in siliciclastic rocks have been studied assuming that intergranular pressure-solution is the dominant process of chemical deformation in sandstones, controlled by temperature and effective stresses. Numerical simulations of section 3.3 emphasized two different scenarios according to the permeability of each depositional environment resulting from different amounts of sandy and shaly sediments. The low permeability scenario presented early overpressure development as a consequence of progressive overburden, reducing effective stresses and preserving sandstone porosities, whereas the more permeable configuration led to higher effective stresses and chemo-mechanical compaction rates, resulting in low porosity and high fluid pressure sandstone formations. Despite the significant difference in the total amount of low permeability material, both configurations presented very similar overpressure distribution in the deepest sandstone compartments.

The limit case analyzed in section 3.4 in which IPS was totally inhibited (theoretically attributed to the presence of clay minerals promoting grain coating) allowed to quantify the overpressure build-up associated to pressure-solution through comparison with the corresponding original model of section 3.3. The results indicated that chemo-mechanical deformation led to an increase of more than $70 \%$ in the overpressure distribution along several sandstone compartments of the basin. An interesting remark is the fact that the chemically-induced compaction at deep layers affects deformation in the upper part of the basin controlled by purely mechanical compaction, as well as the effective stress and overpressure states. This is an important aspect regarding sedimentary basin modeling as it may lead to significant differences in the thermo-poro-mechanical evolution of the numerical model during the reproduction of the geological history of the basin.

Differently from the case of the Garn Formation presented by Schneider and Hay (2001), the overpressure generated by porosity reduction resulting from quartz cementation did not induce fracturing of the overlying low permeability rocks. However, keeping in mind that the numerical simulations were carried out in the simplified framework of a column under oedometric conditions, the possibility for the hydrofracturing phenomenon to occur in the case of a more complex geological situation is not disregarded. The resulting overpressure build-up associated with chemical compaction could be sufficiently high to promote top seal fracturing and leakage, which in turn would affect fluid migration and hydrocarbon distribution within the basin.

Although divergences still exist regarding the factors controlling chemically-induced deformation in several sedimentary rocks, further progress must be achieved to properly deal with this important diagenetic process in basin modeling. The present thermo-poromechanical model may be viewed as a preliminary attempt to couple purely mechanical and chemo-mechanical deformation in sedimentary basins within a tridimensional setting. The implemented constitutive and computational modeling takes into account local coupling effects between effective stresses, pore fluid pressure and temperature in the assessment of overall basin evolution. Different issues still remain to be addressed from both theoretical and numerical viewpoints. In that respect, the development of a viscoplastic flow rule based on alternative yield surface shape and hardening law to model chemical compaction in sedimentary basins involving some specific rocks is the object of on-going research. 


\section{REFERENCES}

Adachi, T., Oka, F., 1982. Constitutive equations for normally consolidated clay based on elasto-viscoplasticity. Soils and Foundations, vol. 22, n. 4, pp. 57-70.

Angevine, C. L., Turcotte, D. L., 1983. Porosity reduction by pressure solution: a theoretical model for quartz arenites. Geological Society of America Bulletin, vol. 94, pp. 1129-1134.

Anzalone, A., Boles, J., Greene, G., Young, K., Israelachvili, J., Alcantar, N., 2006. Confined fluids and their role in pressure solution. Chemical Geology, vol. 230, pp. 220-231.

Barthélémy, J. F., Dormieux, L., Maghous, S., 2003. Micromechanical approach to the modelling of compaction at large strains. Computers and Geotechnics, vol. 30, pp. 321-338.

Bathe, K. J., 1996. Finite element procedures. Prentice-Hall: Upper Saddle River.

Bernaud, D., Deudé, V., Dormieux, L., Maghous, S., Schmitt, D. P., 2002. Evolution of elastic properties in finite poroplasticity and finite element analysis. International Journal for Numerical and Analytical Methods in Geomechanics, vol. 26, pp. 845-871.

Bernaud, D., Dormieux, L., Maghous, S., 2006. A constitutive and numerical model for mechanical compaction in sedimentary basins. Computers and Geotechnics, vol. 33, pp. 316329.

Bjorkum, P. A., 1996. How important is pressure in causing dissolution of quartz in sandstones? Journal of Sedimentary Research, vol. 66, pp. 147-154.

Bjorkum, P. A., Nadeau, P. H., 1998. Temperature controlled porosity/permeability reduction, fluid migration, and petroleum exploration in sedimentary basins. The APPEA Journal, vol. 38, pp. 453-465.

Bjorkum, P. A., Oelkers, E. H., Nadeau, P. H., Walderhaug, O., Murphy, W. M., 1998. Porosity prediction in quartzose sandstones as a function of time, temperature, depth, stylolite frequency, and hydrocarbon saturation. AAPG Bulletin, vol. 82, pp. 637-648.

Bjorlykke, K., 2014. Relationships between depositional environments, burial history and rock properties. Some principal aspects of diagenetic process in sedimentary basins. Sedimentary Geology, vol. 301, pp. 1-14.

Bloch, S., Lander, R. H., Bonnell, L., 2002. Anomalously high porosity and permeability in deeply buried sandstone reservoirs: Origin and predictability. AAPG Bulletin, vol. 86, pp. 301-328.

Boer, R. B. de, Nagtegaal, P. J. C., Duyvis, E. M., 1977. Pressure solution experiments on quartz sand. Geochimica et Cosmochimica Acta, vol. 41, pp. 257-264.

Brüch, A., Maghous, S., Ribeiro, F. L. B., Dormieux, L., 2016. A constitutive model for mechanical and chemo-mechanical compaction in sedimentary basins and finite element analysis. International Journal for Numerical and Analytical Methods in Geomechanics, vol. 40, pp. 2238-2270.

Brüch, A., Maghous, S., Ribeiro, F. L. B., Dormieux, L., 2018. A thermo-poro-mechanical constitutive and numerical model for deformation in sedimentary basins. Journal of Petroleum Science and Engineering, vol. 160, pp. 313-326.

Chapman, B., Jost, G., Pas, R. van der, 2008. Using OpenMP: portable shared memory parallel programming. The MIT Press: Cambridge. 
Chuhan, F. A., Kjeldstad, A., Bjorlykke, K., Hoeg, K., 2002. Porosity loss in sand by grain crushing - experimental evidence and relevance to reservoir quality. Marine and Petroleum Geology, vol. 19, pp. 39-53.

Coussy, O., 2004. Poromechanics. John Wiley \& Sons Ltd: Chichester.

Crook, A. J. L., Obradors-Prats, J., Somer, D., Peric, D., Lovely, P., Kacewicz, M., 2018. Towards an integrated restoration/forward geomechanical modelling workflow for basin evolution prediction. Oil \& Gas Science and Technology - Rev. IFP Energies nouvelles, vol. 73,18 .

Daniel, R. B., 2001. Pressure prediction for a Central Graben wildcat well, UK North sea. Marine and Petroleum Geology, vol. 18, pp. 235-250.

Deudé, V., Dormieux, L., Maghous, S., Barthélémy, J. F., Bernaud, D., 2004. Compaction process in sedimentary basins: the role of stiffness increase and hardening induced by large plastic strains. International Journal for Numerical and Analytical Methods in Geomechanics, vol. 28, pp. 1279-1303.

Dewers, T., Hajash, A., 1995. Rate laws for water-assisted compaction and stress-induced water-rock interaction in sandstones. Journal of Geophysical Research, vol. 100(B7), pp. 13093-13112.

Dormieux, L., Maghous, S., 1999. Poroelasticity and poroplasticity at large strains. Oil \& Gas Science and Technology-Revue de l'IFP, vol. 54, n. 6, pp. 773-784.

Dormieux, L., Maghous, S., 2000. Evolution of elastic properties in finite poroplasticity. C.R. Acad. Sci. Paris, vol. 328(IIb), pp. 593-600.

Dove, P. M., 1999. The dissolution kinetics of quartz in aqueous mixed cation solutions. Geochimica et Cosmochimica Acta, vol. 63,pp. 3715-3727.

Dowey, P. J., Hodgson, D. M., Worden, R. H., 2012. Pre-requisites, processes, and prediction of chlorite grain coatings in petroleum reservoirs: A review of subsurface examples. Marine and Petroleum Geology, vol. 32, pp. 63-75.

Ehrenberg, S. N., 1993. Preservation of anomalously high porosity in deeply buried sandstones by grain-coating chlorite: examples from the Norwegian Continental Shelf. AAPG Bulletin, vol. 77, pp. 1260-1286.

Felippa, C. A., Park, K. C., Farhat, C., 2001. Partitioned analysis of coupled mechanical systems. Computer Methods in Applied Mechanics and Engineering, vol. 190, pp. 32473270 .

Gallagher, K., Ramsdale, M., Lonergan, L., Morrow, D., 1997. The role of thermal conductivity measurements in modelling thermal histories in sedimentary basins. Marine and Petroleum Geology, vol. 14, pp. 201-214.

Gavrilenko, P., Gueguen, Y., 1993. Fluid overpressures and pressure solution in the crust. Tectonophysics, vol. 217, pp. 91-110.

Goulty, N. R., Sargent, C., 2016. Compaction of diagenetically altered mudstones - Part 2: Implications for pore pressure estimation. Marine and Petroleum Geology, vol. 77, pp. 806818.

Goulty, N. R., Sargent, C., Andras, P., Aplin, A. C., 2016. Compaction of diagenetically altered mudstones - Part 1: Mechanical and chemical contributions. Marine and Petroleum Geology, vol. 77, pp. 703-713. 
Gratier, J. P., Irigm, R. G., 1986. Experimental pressure solution-deposition on quartz grains: the crucial effect of the nature of the fluid. Journal of Structural Geology, vol. 8, pp. 845-856.

Gundersen, E., Renard, F., Dysthe, D. K., Bjorlykke, K., Jamtveit, B., 2002. Coupling between pressure solution creep and diffusive mass transport in porous rocks. Journal of Geophysical Research, vol. 107(B11), pp. ECV 19-1-ECV 19-19.

Hamilton, E. L., 1959. Thickness and consolidation of deep-sea sediments. Bulletin of the Geological Society of America, vol. 70, pp. 1399-1424.

Hashin, Z., 1983. Analysis of composite materials - a survey. Journal of Applied Mechanics, vol. 50, pp. 481-505.

Kalani, M., Jahren, J., Mondol, N. H., Faleide, J. I., 2015. Compaction processes and rock properties in uplifted clay dominated units - the Egersund Basin, Norwegian North Sea. Marine and Petroleum Geology, vol. 68, pp. 596-613.

Lander, R. H., Walderhaug, O., 1999. Predicting porosity through simulating sandstone compaction and quartz cementation. AAPG Bulletin, vol. 83, pp. 433-449.

Lehner, F. K., 1995. A model for intergranular pressure solution in open systems. Tectonophysics, vol. 245, pp. 153-170.

Maast, T. E., 2017. Overpressure preventing quartz cementation? - Comment to Stricker et al. (2016). Marine and Petroleum Geology, vol. 79, pp. 335-336.

Maghous, S., Brüch, A., Bernaud, D., Dormieux, L., Braun, A. L., 2014. Two-dimensional finite element analysis of gravitational and lateral-driven deformation in sedimentary basins. International Journal for Numerical and Analytical Methods in Geomechanics, vol. 38, pp. $725-746$.

Meng, Y., Xu, C., Xie, H., Tian, W., Tong, C., Liu, J., Wang, Y., Gao, Y., 2003. A new kinetic model for authigenic quartz formation under overpressure. Petroleum Exploration and Development, vol. 40, pp. 751-757.

Mondol, N. H., Bjorlykke, K., Jahren, J., Hoeg, K., 2007. Experimental mechanical compaction of clay mineral aggregates-Changes in physical properties of mudstones during burial. Marine and Petroleum Geology, vol. 24, pp. 289-311.

Mullis, A. M., 1993. Determination of the rate-limiting mechanism for quartz pressure dissolution. Geochimica et Cosmochimica Acta, vol. 57, pp. 1499-1503.

Nakashima, S., 1995. Diffusivity of ions in pore water as a quantitative basis for rock deformation rate estimates. Tectonophysics, vol. 245, pp. 185-203.

Neveux, L., Grgic, D., Carpentier, C., Pironon, J., Girard, J. P., 2014. Influence of hydrocarbon injection on the compaction by pressure-solution of a carbonate rock: An experimental study under triaxial stresses. Marine and Petroleum Geology, vol. 55, pp. 282294.

Niemeijer, A. R., Spiers, C. J., Bos, B., 2002. Compaction creep of quartz sand at $400-600^{\circ}$ C: experimental evidence for dissolution-controlled pressure solution. Earth and Planetary Science Letters, vol. 195, pp. 261-275.

Nooraiepour, M., Mondol, N. H., Hellevang, H., Bjorlykke, K., 2017. Experimental mechanical compaction of reconstituted shale and mudstone aggregates: Investigation of petrophysical and acoustic properties of SW Barents Sea cap rock sequences. Marine and Petroleum Geology, vol. 80, p. 265-292. 
Obradors-Prats, J., Rouainia, M., Aplin, A. C., Crook, A. J. L., 2017. Assessing the implications of tectonic compaction on pore pressure using a coupled geomechanical approach. Marine and Petroleum Geology, vol. 79, pp. 31-43.

Osborne, M. J., Swarbrick, R. E., 1999. Diagenesis in North Sea HPHT clastic reservoirs consequences for porosity and overpressure prediction. Marine and Petroleum Geology, vol. 16, pp. 337-353.

Perzyna, P., 1966. Fundamental problems in viscoplasticity. Advances in Applied Mechanics, vol. 9, pp. 243-277.

Raj, R., 1982. Creep in polycrystalline aggregates by matter transport through a liquid phase. Journal of Geophysical Research, vol. 87, pp. 4731-4739.

Ramm, M., 1992. Porosity-depth trends in reservoir sandstones: theoretical models related to Jurassic sandstones offshore Norway. Marine and Petroleum Geology, vol. 9, pp. 553-567.

Ramm, M., Bjorlykke, K., 1994. Porosity/depth trends in reservoir sandstones: assessing the quantitative effects of varying pore-pressure, temperature history and mineralogy, Norwegian Shelf data. Clay Minerals, vol. 29, pp. 475-490.

Renard, F., Ortoleva, P., Gratier, J. P., 1997. Pressure solution in sandstones: influence of clays and dependence on temperature and stress. Tectonophysics, vol. 280, pp. 257-266.

Renard, F., Park, A., Ortoleva, P. Gratier, J.-P., 1999. An integrated model for transitional pressure solution in sandstones. Tectonophysics, vol. 312, pp. 97-115.

Rutter, E. H., 1976. The kinetics of rock deformation by pressure solution. Philosophical Transactions of the Royal Society of London, vol. 283, pp. 203-219.

Rutter, E. H., 1983. Pressure solution in nature, theory and experiment. Journal of the Geological Society, vol. 140, pp. 725-740.

Schmidt, V., McDonald, D. A., 1979. The role of secondary porosity in the course of sandstone diagenesis. Aspects of Diagenesis, vol. 26, pp. 175-207.

Schneider, F., Hay, S., 2001. Compaction model for quartzose sandstones application to the Garn Formation, Haltenbanken, Mid-Norwegian Continental Shelf. Marine and Petroleum Geology, vol. 18, pp. 833-848.

Schneider, F., Potdevin, J. L., Wolf, S., Faille, I., 1996. Mechanical and chemical compaction model for sedimentary basin simulators. Tectonophysics, vol. 263, pp. 307-317.

Schutjens, P. M. T. M., Spiers C. J., 1999. Intergranular pressure solution in NaCl: grain-tograin contact experiments under the optical microscope. Oil \& Gas Science and TechnologyRevue de l'IFP; vol. 54, pp. 729-750.

Sclater, J. G., Christie P. A. F., 1980. Continental stretching: an explanation of the Post-MidCretaceous subsidence of the central North Sea Basin. Journal of Geophysical Research, vol. 85(B7), pp. 3711-3739.

Sheldon, H. A., Wheeler, J., Worden, R. H., Cheadle, M. J., 2003. An analysis of the roles of stress, temperature, and $\mathrm{pH}$ in chemical compaction of sandstones. Journal of Sedimentary Research, vol. 73, pp. 64-71.

Shimizu, I., 1995. Kinetics of pressure solution creep in quartz: theoretical considerations. Tectonophysics, vol. 245, pp. 121-134. 
Stransky, J., Vorel, J., Zeman, J., Sejnoha, M., 2011. Mori-Tanaka based estimates of effective thermal conductivity of various engineering materials. Micromachines, vol. 2, n. 2, pp. 129-149.

Stricker, S., Jones, S. J., 2016. Enhanced porosity preservation by pore fluid overpressure and chlorite grain coatings in the Triassic Skagerrak, Central Graben, North Sea, UK. Geological Society, London, Special Publications, vol. 435, pp. 321-341.

Stricker, S., Jones, S. J., Grant, N. T., 2016. Importance of vertical effective stress for reservoir quality in the Skagerrak Formation, Central Graben, North Sea. Marine and Petroleum Geology, vol. 78, pp. 895-909.

Stricker, S., Jones, S. J., Sathar, S., 2017. Overpressure preventing quartz cementation? - A reply. Marine and Petroleum Geology, vol. 79, pp. 337-339.

Tada, R., Siever, R., 1989. Pressure solution during diagenesis. Annual Review of Earth and Planetary Sciences, vol. 17, pp. 89-118.

Ulamec, S., Biele, J., Funke, O., Engelhardt, M., 2007. Access to glacial and subglacial environments in the Solar System by melting probe technology. Reviews in Environmental Science and Bio/Technology, vol. 6, pp. 71-94.

Walderhaug, O., Lander, R. H., Bjørkum, P. A., Oelkers, E. H., Bjørlykke, K., Nadeau, P. H., 2000. Modelling quartz cementation and porosity in reservoir sandstones: examples from the Norwegian Continental Shelf. In Quartz Cementation in Sandstones (eds R. H. Worden and S. Morad).

Wangen, M., 2000. Generation of overpressure by cementation of pore space in sedimentary rocks. Geophysical Journal International, vol. 143, pp. 608-620.

Weyl, P. K., 1959. Pressure solution and the force of crystallization - a phenomenological theory. Journal of Geophysical Research, vol. 64, pp. 2001-2025.

Wood, D. M., 1990. Soil Behaviour and Critical State Soil Mechanics. Cambridge University Press, Cambridge.

Wooldridge, L. J., Worden, R. H., Griffiths, J., Utley, J. E. P., 2017. Clay-coated sand grains in petroleum reservoirs: understanding their distribution via a modern analogue. Journal of Sedimentary Research, vol. 87, pp. 338-352.

Worden, R. H., Morad, S., 2000. Quartz cementation in oil field sandstones: a review of the key controversies. In Quartz Cementation in Sandstones (eds R. H. Worden and S. Morad).

Yang, X. S., 2000. Pressure solution in sedimentary basins: effect of temperature gradient. Earth and Planetary Science Letters, vol. 176, pp. 233-243.

Yin, Z. Y., Hicher, P. Y., 2008. Identifying parameters controlling soil delayed behaviour from laboratory and in situ pressuremeter testing. International Journal for Numerical and Analytical Methods in Geomechanics, vol. 32, pp. 1515-1535.

Zhang, X., Spiers, C. J., 2005. Compaction of granular calcite by pressure solution at room temperature and effects of pore fluid chemistry. International Journal of Rock Mechanics \& Mining Sciences, vol. 42, pp. 950-960.

Zienkiewicz, O. C., Taylor, R. L., 2000. The Finite Element Method V.1: The Basis. 5th ed. Butterworth-Heinemann: Oxford. 